\title{
TUNEL assay-Standardized method for testing sperm DNA fragmentation
}

\author{
Rakesh Sharma $^{1}$ (D) | Concetta lovine ${ }^{1}$ (D) $\mid$ Ashok Agarwal ${ }^{1}$ (D) | Ralf Henkel ${ }^{1,2}$ (i)
}

\author{
${ }^{1}$ American Center for Reproductive \\ Medicine, Cleveland Clinic, Cleveland, $\mathrm{OH}$, \\ USA \\ ${ }^{2}$ Department of Medical Bioscience, \\ University of the Western Cape, Bellville, \\ South Africa

\section{Correspondence} \\ Ashok Agarwal, Andrology Center and \\ American Center for Reproductive \\ Medicine, 10681 Carnegie Avenue, Desk \\ X11; Cleveland, Ohio 44195, USA. \\ Email: agarwaa@ccf.org
}

\begin{abstract}
Sperm DNA integrity is important for normal functions such as fertilization, implantation, pregnancy and fetal development. Sperm DNA fragmentation (SDF) is more common in infertile men and may be responsible for poor reproductive function. Although there are a number of tests available to measure SDF, the terminal deoxynucleotidyl transferase-mediated deoxyuridine triphosphate-nick end labelling TUNEL) assay using flow cytometry is becoming more popular to measure the sperm DNA fragmentation. It is a direct test that measures both single- and double- DNA strand breaks. In this review, we describe the protocol, quality control and measurement of sperm DNA fragmentation using a benchtop flow cytometer. We also briefly discuss the factors that can affect the results, challenges and clinical implications of TUNEL in assessing male infertility.
\end{abstract}

\section{KEYWORDS}

DNA fragmentation, flow cytometer, male infertility, sperm, TUNEL assay

\section{1 | BACKGROUND}

\section{1 | Overview of semen analysis: Diagnostic value and limitations}

Routine semen analysis consists of measurement of volume, concentration, motility, morphology and vitality. This evaluation is extremely subjective and requires trained technicians as well as regularly performed quality assurance assessments (Douglas, Parekh, Kahn, Henkel, \& Agarwal, 2019). The results can be affected by errors due to operator inexperience and lack of standardized protocols (Tomlinson, 2016). A significant overlap is seen in basic semen parameters between fertile and infertile men (Nallella, Sharma, Aziz, \& Agarwal, 2006). Therefore, traditional semen analysis cannot identify the molecular and cellular mechanisms involved in fertilization and fertility. Tests such as sperm penetration assay, acrosome reaction and the hemizona assay have become redundant with the introduction of assisted reproductive techniques such as intracytoplasmic sperm injection (ICSI) (Vogiatzi et al., 2013). New technologies such as automated semen analyzers, use of smartphones for semen testing, microfluidics and proteomics fail to predict male fertility with 100\% accuracy (Segerink, Sprenkels, Oosterhuis, Vermes, \& van den Berg, 2012). Therefore, diagnostic tools that can better discriminate fertile from infertile men and predict pregnancy outcome are desired. The test with the greatest potential appears to be the assessment of DNA integrity. Sperm lipids, proteins and nucleic acids are potential targets of oxidative stress because of the presence of ROS in all tissues (Figure 1; Tremellen, 2008). Oxidative stress is a major contributor of sperm DNA fragmentation (SDF) (Tremellen, 2008). SDF negatively impacts semen parameters and reproductive potential (Cho \& Agarwal, 2017). In the last 10 years, sperm DNA integrity has become a powerful and helpful marker of sperm function (Agarwal \& Said, 2003). In this review, we describe the common methods to analyze sperm DNA integrity with special emphasis on TUNEL as a method of choice for measuring DNA fragmentation using bench flow cytometer. In addition, the methodology, quality control, challenges and the clinical implications of TUNEL in assessing male infertility are also discussed. 


\subsection{What clinical value does sperm DNA fragmentation testing provide?}

Spermiogenesis is a complex process where the immature spermatids are transformed into mature spermatozoa. It is comprised of the Golgi, the cap, the acrosome and the flagellar (maturation) phase. There is a progressive condensation and compaction of chromatin with a significant reduction of nuclear volume, blocking of transcription and resistance of DNA to digestion. These DNA modifications are correlated with the replacement of histones with basic protamines and the elimination of the excessive residual cytoplasm. A mature and normal spermatozoon must be able to fertilize a mammalian oocyte in order to develop an embryo (Wdowiak \& Bojar, 2016). Sperm DNA integrity tests are important in the clinical evaluation of male fertility. These tests include the sperm chromatin structure assay (SCSA) (Evenson, 1999), the single-cell gel electrophoresis assay (comet assay) (Simon, Zini, Dyachenko, Ciampi, \& Carrell, 2017), the sperm chromatin dispersion (SCD) test (Fernández et al., 2003, 2005) and the terminal deoxynucleotidyl transferase-mediated deoxyuridine triphosphate-nick end labelling (TUNEL) assay (Sharma, Ahmad, Esteves, \& Agarwal, 2016; Sharma et al., 2018, Sharma, Gupta, Henkel, \& Agarwal, 2019).

Recently, an expert panel studied the value of including SDF in the evaluation of infertility (Agarwal, Majzoub, et al., 2016). The panel made practice recommendations based on different clinical scenarios to include SDF testing for (a) men with normal semen parameters and high-grade varicocele or abnormal semen parameters and lowgrade varicocele, (b) unexplained infertility, (c) recurrent pregnancy loss, (d) recurrent intrauterine (IUI) failures, (e) in vitro fertilization (IVF) and ICSI failures and (f) men with lifestyle risk factors (Agarwal, Majzoub, et al., 2016). Although the impact of SDF testing is evident in the evaluation of male infertility, reproductive societies such as the American Society for Reproductive Medicine (ASRM), European
Association of Urology (EAU), American Urological Association (AUA) and National Institute of Clinical Excellence (NICE) do not recommend including SDF in the routine assessment of fertility. However, it is extremely important to develop good methodological studies to standardize the utility of SDF testing in the clinical evaluation of infertile men to allow the test to play a routine role in the workup of the infertile male.

\section{2 | TYPES OF SPERM DNA DAMAGE}

\section{1 | DNA fragmentation}

Oxidative stress is a major contributor of sperm DNA fragmentation in infertile men (Aitken \& De luliis, 2010; Wright, Milne, \& Leeson, 2014). The chances to conceive naturally or by ART procedures such as IUI, IVF and ICSI are significantly reduced in men with high SDF.

\section{2 | Abnormal chromatin compaction}

Sperm chromatin is highly compacted during spermatogenesis by the replacement of nuclear histones with protamines. Protamines are basic proteins containing numerous cysteine and arginine residues that are present in small quantities in the immature germ cells (Frajese, Silvestroni, Malandrino, \& Isidori, 1976). This unique packaging allows sperm cells to maintain compact structure, which confers stability, and occupies almost the total nucleus volume. Chromatin stability is essential for preserving sperm fertility potential and to ensure fertilization and embryonic development (Erenpreiss, Spano, Erenpreisa, Bungum, \& Giwercman, 2006; Zini \& Sigman, 2009).

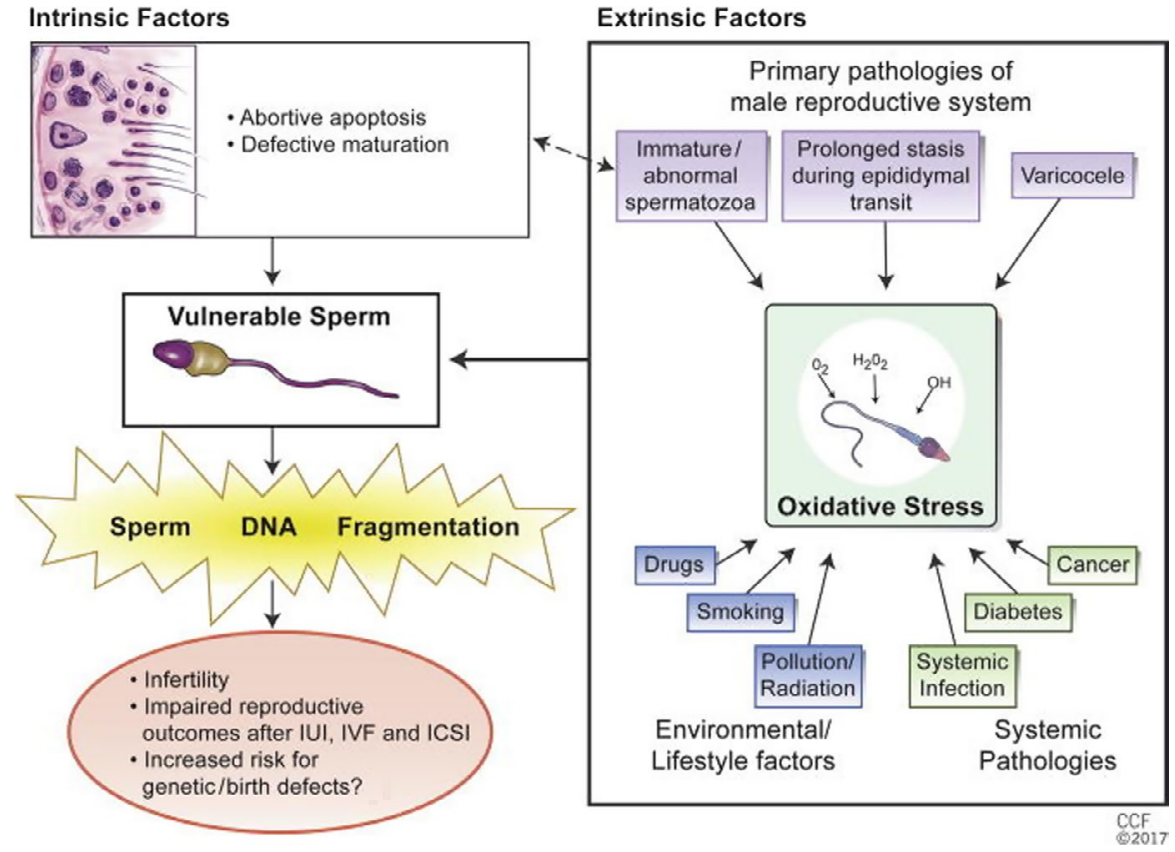

FIGURE 1 Mechanisms of ROSinduced impairments in sperm functions 


\section{3 | Chromosomal aberrations}

Chromosomal aberrations in the germinal line are a major contributor to male infertility. Aneuploidies are examples of chromosomal aberrations caused by disjunction failure of homologous chromosomes or sister chromatids during meiosis or mitosis, respectively. The intratesticular environment can negatively affect the mechanisms responsible for chromosome segregation during cell division generating abnormal chromosome even when the somatic karyotype is normal (Calogero, Burrello, De Palma, Barone, \& Vicari, 2003). Chromosomal abnormalities of male gametes negatively affect pregnancy and implantation rates as well as fetal survival (Calogero et al., 2001; Rubio et al., 2001). In couples with recurrent pregnancy loss, the phenomenon is correlated with an increase in the rate of sex chromosome disomy in the spermatozoa of male partners (Rubio et al., 1999).

\section{3 | CAUSES OF SPERM CHROMATIN DAMAGE (FIGURE 1)}

\subsection{Meiotic recombination}

Aneuploidies increase the risk of achieving a healthy pregnancy and obtaining a fetus without anomalies. Most of these aneuploidies are associated with improper meiotic recombination (Carrell, 2008). Topping et al. investigated meiotic progression and recombination rates in control males and compared it with a group of males with non-obstructive azoospermia (NOA) or severe oligozoospermia. In the majority of cases, meiosis proceeds normally, until the first meiotic division; however, in about $10 \%$ of cases, a partial-to-complete meiotic arrest (no germ cells) was observed in zygotene or pachytene stage. These meiotic errors are main contributory factors for male infertility. Defects in meiotic recombination may help explain NOA where a total meiotic arrest was observed as a result of synaptonemal abnormalities (Topping et al., 2006).

\section{2 | Abortive apoptosis}

Apoptosis or programmed cell death is a spontaneous event that occurs during the wave of seminiferous epithelium. Each of these 4 waves is approximately 16 days, and hence, the total duration is 64 days. Spermatogenesis involves proliferation, maturation and differentiation that transforms an immature diploid sperm cells into mature haploid spermatozoa. During some phases of spermatogenesis, apoptosis controls sperm production within testis (Shukla, Mahdi, \& Rajender, 2012). During normal spermatogenesis, excessive residual cytoplasm is eliminated by phagocytosis before the spermatozoa are released in the lumen for transport in the epididymis. Abnormal spermatozoa with excessive cytoplasm, which are destined to be eliminated, can escape apoptosis and appear in the ejaculate in a phenomena termed as abortive apoptosis. When the apoptotic index is very high ( $>40 \%$ ), the probability of achieving a pregnancy by IUI is significantly decreased, and the probability of spontaneous abortions in cases of IVF or ICSI is increased. The apoptosis process is regulated at 3 levels:

1. At the cell membrane level-Fas receptors of tumor necrosis factor receptor (TNFR) family are present on the germ cells and Sertoli cells

2. At the cytoplasmic level-involving some proteases of the 'caspase' family

3. At the nuclear level-there are apoptosis regulatory genes such as p53 and Bcl-2. If DNA damage cannot be repaired, p53 triggers the cell death process by inducing the binding of the Fas ligand to the Fas membrane receptor (Sakkas \& El-Fakahany, 2018; Sakkas, Seli, Bizzarro, Tarozzi, \& Manicardi, 2003).

\section{3 | Oxidative stress}

High levels of reactive oxygen species (ROS) are reported in $25 \%$ to $40 \%$ of semen samples from infertile men (Mahfouz et al., 2010). High levels of ROS overwhelm the antioxidant defences of the seminal plasma and result in oxidative stress (OS). Leukocytes and abnormal spermatozoa are the main producers of ROS. Semen samples may contain a variable number of leukocytes, predominantly neutrophils, which generate high levels of ROS (Sharma, Pasqualotto, Nelson, \& Agarwal, 2001). Leukocytospermia is a condition when $>1 \times 10^{6}$ white blood cells/ $\mathrm{mL}$ of semen are present (WHO, 2010). It is correlated with oxidative stress and reduced sperm concentration, motility and morphology (Lanzafame, La Vignera, Vicari, \& Calogero, 2009). The seminal plasma is rich in antioxidants and provides nutrition as well as a protective environment essential for sperm motility. In contrast, infertile men have reduced antioxidants and DNA repair enzymes (Zini \& Al-Hathal, 2011).

Immature spermatozoa produce higher levels of ROS compared to mature spermatozoa, inducing DNA damage in mature spermatozoa. This process can occur during the transit of mature and immature spermatozoa from the seminiferous tubules to the epididymis due to the close proximity of the spermatozoa (Sakkas \& Alvarez, 2010). Spermatozoa are highly specialized cells that are poorly equipped with antioxidant defence mechanisms and are therefore more susceptible to oxidative stress, as they lack cytoplasm and the membrane is rich in polyunsaturated fatty acids. All of these changes result in a reduced fertilizing capacity, pregnancy loss or in some cases, genetic mutations of the embryo (Agarwal, Virk, Ong, \& du Plessis, 2014).

\subsection{Other intrinsic and extrinsic factors}

DNA damage can be due to other intrinsic (e.g. varicocele, spinal cord injury, diabetes) and extrinsic factors (e.g. lifestyle, infections, 
TABLE 1 Assays used to evaluate sperm DNA fragmentation

\begin{tabular}{ll} 
Test & Test principle \\
\hline $\begin{array}{l}\text { DIRECT } \\
\text { comet assay }\end{array}$ & $\begin{array}{c}\text { Evaluates the integrity of DNA, double- and } \\
\text { single-strand breaks } \\
\text { Evaluates DNA fragmentation, double- and } \\
\text { single-strand breaks }\end{array}$ \\
\hline INDIRECT & $\begin{array}{c}\text { Evaluates the susceptibility of sperm DNA } \\
\text { to acid denaturation }\end{array}$ \\
SCSA & $\begin{array}{c}\text { Evaluates the susceptibility of sperm DNA } \\
\text { to acid denaturation } \\
\text { Evaluates double- and single-strand breaks }\end{array}$ \\
\hline
\end{tabular}

Abbreviations: AOT: acridine orange test; SCSA: sperm chromatin structure assay; SCD: sperm chromatin dispersion; TUNEL: terminal deoxynucleotidyl transferase dUTP nick end labelling

exposure to xenobiotics) (Zini \& Sigman, 2009). Other causes of sperm DNA damage include apoptosis, post-testicular DNA fragmentation due to endogenous endonuclease or by radiotherapy and chemotherapy (Alvarez, 2005).

Sperm DNA damage is likely a major contributing factor for infertility in men with clinical varicoceles (Dieamant et al., 2017; Saleh et al., 2003; Wang, Zhang, Zhang, Lin, Zhang, \& Zhang, 2012). In varicocele patients, the number of apoptotic spermatozoa is higher compared to those without varicocele (Lin, Dhabuwala, \& Li, 2001). The presence of abnormal DNA and immature chromatin is associated with elevated intratesticular temperature during spermiogenesis. This can induce sperm DNA denaturation and damage chromatin packaging (Gual-Frau et al., 2015).

Sperm parameters can be compromised as a result of diabetes. According to Zhu et al., semen volume, motility and vitality in insulin-dependent diabetes are significantly decreased (Zhu et al. 2017). High DNA fragmentation is reported in diabetic patients compared to those without diabetes and is largely attributed to increased oxidative stress levels in these men (Zhu et al. 2017).

Environmental factors also contribute to sperm chromatin damage and sperm abnormality. Xenobiotic, or synthetic, compounds can affect spermatozoa through occupational, pharmacological or environmental exposure. For example, benzene is a compound present in industrial chemical substances such as petroleum products. It is a toxic compound that is found in the environment as it comes from the emissions of gas oil, the combustion of hydrocarbons and cigarette smoke. It can induce DNA fragmentation and results in a reduction in motility and vitality (Mandani, Desai, \& Highland, 2013).

Diseases affecting the reproductive system (varicocele, prostatitis, epididymitis, vesiculitis), unhealthy lifestyle habits (smoking, alcohol, drugs), and environmental and food pollution (radiation, smog, industrial gases) represent the main sources of stress for spermatozoa (Mostafa et al., 2006; Saleh, Agarwal, Sharma, Nelson, \& Thomas, 2002; $\mathrm{Wu} \&$ Cederbaum, 2003). Infertile men with varicocele have reduced levels of antioxidants in the semen (Abd-Elmoaty, Saleh, Sharma, \&
Agarwal, 2010). Obesity is linked with male infertility. In overweight and obese men, the sperm concentration, normal sperm morphology, semen volume and testosterone levels decrease significantly and DNA fragmentation increases compared to men with normal weight (Cui et al., 2015; Dupont et al., 2013; Zhu et al. 2017). Therefore, identification of risk factors and accurate assessment of sperm DNA damage is important.

\section{4 | EVALUATION OF SPERM CHROMATIN DAMAGE}

\subsection{Overview of tests available (Table 1)}

Table 1 lists the various tests that measure single or double DNA strand breaks. These may be direct or indirect. Direct tests that measure single- and double-strand breaks include TUNEL and the comet assay, whereas indirect tests such as SCSA and SCD measure the susceptibility of DNA to denaturation following acid treatment.

\subsection{What do these tests assess?}

\subsection{1 | comet assay}

The comet assay measures the electrophoretic migration of small DNA fragments. Comet assay can be performed under neutral or alkaline conditions. In this assay, the cells are stained with fluorescent dyes and a total of 400 cells are scored by fluorescent microscopy. In the neutral comet assay, the double-stranded DNA loops migrate from a damaged cell and form a tail that unwinds from the supercoiled nucleus. This unwinding is proportional to the amount of DNA damage. When observed under a fluorescence microscope, it gives the characteristic appearance of a 'comet'. Both single- and double-stranded DNA are exposed under alkaline conditions. A modified two-tailed comet assay (2-T comet assay) can also evaluate the single- and double-stranded DNA breaks (Cortés-Gutiérrez, Fernández, Dávila-Rodríguez, LópezFernández, \& Gosálvez, 2017). Consequently, the cells that have suffered DNA damage appear as comets, where the tail is represented by fragmented DNA and the head is represented by the nucleus, while the control cells show a more spherical and condensed nucleus. DNA migration is a function of both the DNA size and the number of breaking sites, and the length of the tail increases with the damage.

The comet assay is simple, sensitive and rapid and correlates with SCSA and TUNEL assay (Benchaib et al., 2003; Ribas-Maynou et al., 2012). Similarly, the 2-T comet assay is a fast, sensitive and reliable assay that can be used to quantify and characterise sperm DNA damage (Cortés-Gutiérrez et al., 2017). The comet assay is able to predict embryo development following IVF and ICSI in couples with unexplained infertility (Morris, Ilott, Dixon, \& Brison, 2002; Tomsu, Sharma, \& Miller, 2002). The clinical threshold for diagnosing infertility and predicting IVF outcomes has been proposed (Lewis \& Agbaje, 2008; Ribas-Maynou et al., 2012). 


\subsubsection{SCSA test}

The SCSA (sperm chromatin structure assay) test is an indirect test to measure SDF. It measures the susceptibility of sperm DNA to damage induced by acid denaturation, which is detected using metachromatic dye acridine orange (AO). Cells emit a green fluorescence when $\mathrm{AO}$ binds to native double-stranded DNA and red fluorescence when AO binds to damaged single-stranded DNA. Using a flow cytometer, 10,000 spermatozoa are analysed within a few seconds and therefore this test is more rapid, robust and accurate compared to the subjective, microscopic evaluation. The accuracy of the SCSA test is $100 \%$. Patients with SDF $<30 \%$ were 7.1 times more likely to achieve a pregnancy in vivo and 2.0 times $(95 \% \mathrm{Cl}$ ) after ART (Bungum et al. 2004).

The percentage of spermatozoa with fragmented DNA is called the DNA fragmentation index or DFI. A threshold of $<30 \%$ DFI is associated with in vivo pregnancy (Bungum, 2012; Bungum et al., 2007; Castilla et al., 2010; Giwercman et al., 2010). The DFI alone can predict fertility in couples undergoing IUI (Evenson \& Wixon, 2006); however, the correlation between SCSA results and IVF/ ICSI outcomes is not strong (Collins, Barnhart, \& Schlegel, 2008). ICSI is recommended when DFI exceeds 30\% (Bungum et al., 2007).

\subsection{3 $\mid$ SCD test}

The sperm chromatin dispersion (SCD) test is based on the assessment of a central core and peripheral halo produced by the release of DNA loops. When spermatozoa with intact DNA are immersed in an agarose layer and exposed to lysing solutions, deproteinised nuclei or nucleoids exhibit halos of dispersed DNA. These halos can be observed either by bright field or fluorescence microscopy. Spermatozoa with DNA fragmentation do not show the halo (Fernández et al., 2003).

In the improved SCD test, the slides can be stained with Wright's stain and observed under bright field microscopy or using DAPI (4',6-diamidino-2-phenylindole) $(2 \mu \mathrm{g} / \mathrm{ml})$ and observed with fluorescence microscopy (Fernández et al., 2003; Zini et al., 2002). The SCD test is simple, fast and reproducible and results are comparable to SCSA (Fernández et al., 2005; Muriel et al., 2006) and TUNEL assay (Agarwal, Majzoub, et al., 2016). In IVF and ICSI, SCD is negatively correlated with fertilization rate $(-0.245 ; p=.045)$ and implantation rate $(-0.250 ; p=.042)$ but not with clinical pregnancy rates or live birth rates (Muriel et al., 2006; Velez de la Calle et al., 2008).

\subsubsection{How does the TUNEL assay compare to the rest?}

The TUNEL assay is the most common test used for evaluating SDF in spermatozoa as well as several end-point conditions in both natural and assisted reproduction (Baskaran et al., 2019). In a meta-analysis, the TUNEL was the most predictive assay for miscarriage rate, followed by SCSA (Robinson et al., 2012). Another meta-analysis by Osman et al., (Osman, Alsomait, Seshadri, El-Toukhy, \& Khalaf, 2015) showed that the TUNEL assay was the most predictive test for birth rate with ART. The TUNEL test demonstrated a predictive value in clinical pregnancy after IVF/ ICSI, whereas both SCSA and SCD tests showed 'weak' predictive value (Cissen et al., 2016). Therefore, the TUNEL assay has the potential to be a robust diagnostic tool not only for predicting male infertility but also to understand the predictive ability of many other factors that may affect ART outcome related to achieving pregnancy.

\section{5 | TUNEL ASSAY}

\section{1 | Principle of TUNEL assay}

The TUNEL (terminal deoxynucleotidyl transferase-mediated deoxyuridine triphosphate-nick end labelling) assay is a reliable and sensitive method initially developed for measuring DNA damage in somatic cells. It was later modified for use with spermatozoa (Mitchell, De lullis, \& Aitken, 2011). TUNEL assay uses terminal deoxynucleotidyl transferase (TdT), a polymerase that catalyses the addition of fluoresceinated-dUTP at the $3^{\prime}-\mathrm{OH}$ end of the DNA fragments (Figure 2). The assay shows the percentage of cells with damaged DNA (Agarwal, Gupta, \& Sharma, 2016; Sharma, Cakar, \& Agarwal, 2018). The fluorescence intensity of the sperm can be examined by fluorescence microscopy or by flow cytometry. Here, we describe the measurement of DNA damage by TUNEL assay using a benchtop flow cytometer.

\section{2 | Methodology}

\subsection{1 | Sample preparation}

After analyzing the sperm samples for concentration, the concentration is adjusted to $2.5 \times 10^{6}$ spermatozoa and the samples are divided into test and negative controls. The samples are washed twice in phosphate-buffered saline (PBS) (Agarwal, Gupta, Du Plessis, et al., 2016). Samples are centrifuged at $300 \mathrm{~g}$ to remove seminal plasma. After removing the supernatant, $7 \%(\mathrm{w} / \mathrm{v})$ paraformaldehyde (PFA) prepared in PBS is added to the samples. Positive controls are prepared by adding PBS and washing spermatozoa twice with PBS. SDF is induced by adding $2 \%(\mathrm{v} / \mathrm{v})$ hydrogen peroxide $\left(\mathrm{H}_{2} \mathrm{O}_{2}\right)$ and incubating the sample for $1 \mathrm{hr}$ at $50^{\circ} \mathrm{C}$ in a heating block. After incubation, the sample is centrifuged for $7 \mathrm{~min}$ at $300 \mathrm{~g}$ to remove the $\mathrm{H}_{2} \mathrm{O}_{2}$. The sample is washed twice with PBS and the supernatant is then removed. One $\mathrm{ml}$ of PFA is added to the sperm pellet, 'Test', 'Negative' and 'Positive' samples and are then centrifuged at $400 \mathrm{~g}$ for $7 \mathrm{~min}$. The PFA is removed and $70 \%(\mathrm{v} / \mathrm{v})$ ice-cold ethanol is added. The samples can be batched and kept at $-20^{\circ} \mathrm{C}$ (Agarwal, Gupta, Du Plessis, et al., 2016). 


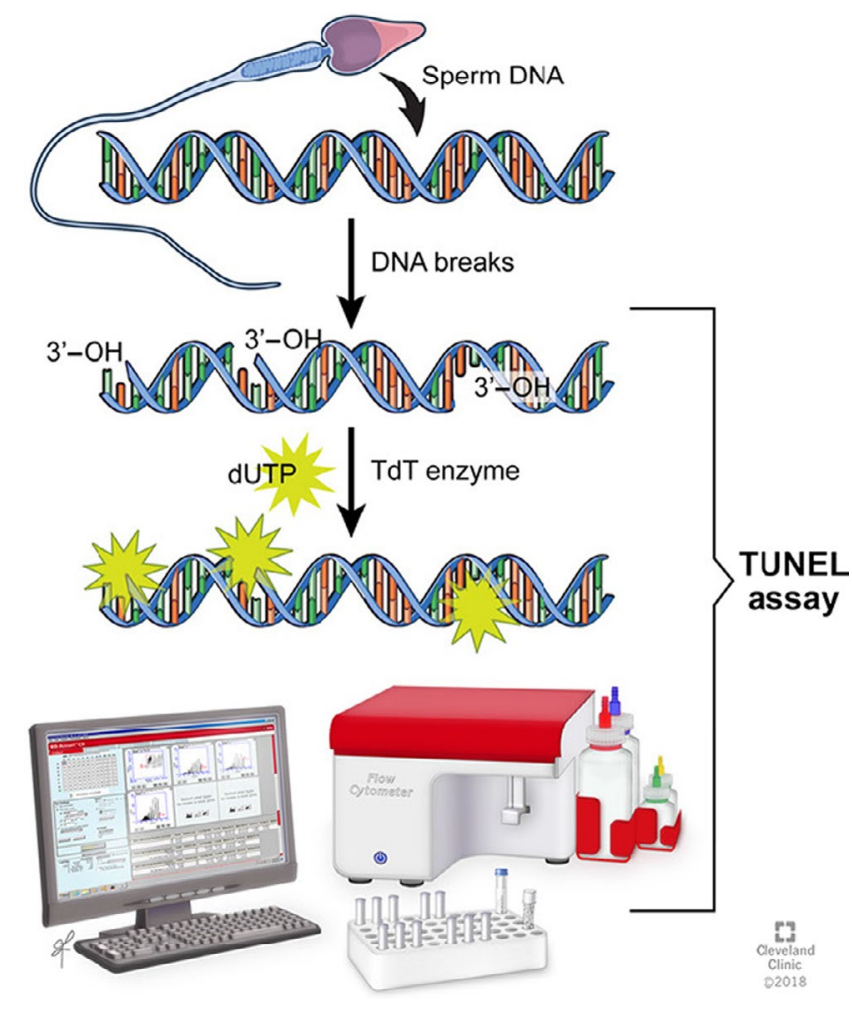

FIGURE 2 Schematic of DNA staining by TUNEL assay

\subsection{2 | Protocol}

SDF can be tested using the Apo-DIRECT ${ }^{\text {TM }}$ kit (Pharmingen) (Agarwal, Gupta, Du Plessis, et al., 2016). Negative and positive controls are included in the kit. These are diploid cells derived from a human lymphoma cell line and are suspended in ethanol. Samples stored in ethanol are brought to room temperature. Kit controls (Negative and Positive controls), test samples and internal controls (spermatozoa with known amount of SDF) are washed twice with 'wash buffer'. The buffer is removed, samples are stained with 50 $\mu l$ of the staining, and incubation is carried out for $60 \mathrm{~min}$ in the dark. The staining solution consists of reaction buffer, TdT enzyme, FITC-dUTP and distilled water prepared according to the manufacturer's instructions. All specimens are incubated and at the end of the incubation, $1 \mathrm{ml}$ of 'rinse buffer' is added and the sample is centrifuged twice. After discarding the supernatant, $0.5 \mathrm{ml}$ of propidium iodide ( $\mathrm{PI}$ )/RNase solution is added and the samples are ready to be tested after $30 \mathrm{~min}$ by flow cytometric analysis.

A total of 10,000 spermatozoa are counted. The settings are as follows: fluidic set at 'slow', flow rate of $<100$ cells per second. A blue laser at $20 \mathrm{~mW}$ provides an excitation at $488 \mathrm{~nm}$ a red laser is powered by $14.7 \mathrm{~mW}$ diode red laser. It provides excitation at $640 \mathrm{~nm}$. There are two channels: FL1 measures Green fluorescence (480-530 nm) and FL2 measures red fluorescence (640 nm). The software provided by the manufacturer generates the dot plots and also calculates the percentage of TUNEL-positive cells (BD Accuri software; BD Biosciences).
Three plots and sequential gating strategy are used (Gupta, Sharma, \& Agarwal, 2017; Figure 3). SDF is expressed as percentage of fragmented DNA.

The three plots used are as follows:

1. Forward scatter versus side scatter or 'Plot 1': Gate is drawn and small debris and larger nonsperm cells are excluded. This selects only spermatozoa with expected size or G1 population. Spermatozoa stained with PI with a flame-shaped gate are gated in the forward scatter (FSC) versus side scatter (SSC) plot (Muratori et al., 2008).

2. PI fluorescence and FSC or 'Plot 2': PI-positive events gating (G2) is applied to gate PI-positive events within the cells belonging to the G1 population. This gating selects only the PI-positive spermatozoa. Debris and M450 apoptotic bodies that lack nuclei do not stain with $\mathrm{PI}$ and are excluded. TUNEL and PI staining exclude the $\mathrm{M} 450$ bodies (Muratori et al., 2015).

3. PI-fluorescence- and FITC-fluorescence-positive gates or 'Plot 3'. The TUNEL and PI-positive samples are in the upper right quadrant (Plot 4).

\subsection{3 | Data analysis}

Data analysis is done as described below:

1. Alignment strategy and data analysis: This is done in the 'Collect' tab. A file consisting of a standard sample with a known amount of DNA fragmentation is imported. The negative peak of the standard sample is applied to all samples as shown in Figure 4.

2. X-axis parameter is changed from FSC-A to FL1-A. For plot 5, the gate is changed to P3 in P1

3. The vertical red line is aligned to the center of the histogram. This equally splits the cell population (50\%) on either side (Figure 4). This is easily accomplished by zooming on the histogram and aligning the red line in the middle of the peak.

4. The sample to be aligned is picked up by right clicking on the $\mathrm{X}$-axis and clicking on the virtual gain. The blue line is aligned to the center of the sample peak (Figure 5).

5. Click on the 'Preview' and next click 'Apply'. After choosing the option 'Apply' only to this sample only. Close and save the changes (Figure 6). After the sample is aligned an asterisk will appear at the bottom of each sample (Figure 7).

6. Each sample is aligned to its respective Negative control.

The acquired data are analysed in the 'Analyze' tab.

When the Analyze tab is opened for the first time, the workspace is empty (Gupta et al., 2017).

The plots are automatically selected from the original template. Original gates are used by copying the plots from the 'Collect' tab. Gating strategies set up in the Collect tab are applied in the Analyze tab. A three-plot group for each sample is created: 


\section{Collect}

\section{A01}

$\begin{array}{llllllllllll}1 & 2 & 3 & 4 & 5 & 6 & 7 & 8 & 9 & 10 & 11 & 12\end{array}$

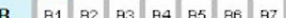

$\begin{array}{lllllllllllllll}\text { C } & C 1 & C 2 & C 3 & C 4 & C 5 & C 6 & C 7 & C 8 & C 9 & C 10 & C 11 & C 12\end{array}$

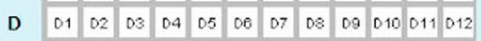

$\begin{array}{llllllllllllllll}\text { E } & \text { E1 } & \text { E2 } & \text { E3 } & \text { E4 } & \text { E5 } & \text { E6 } & \text { E7 } & \text { Es } & \text { E9 } & \text { E10 } & \text { E11 } & \text { E12 }\end{array}$

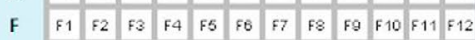

$\begin{array}{llllllllllllllll}\text { G } & G 1 & G 2 & G S & G 4 & G 5 & G 6 & G 7 & G 8 & G 9 & G 10 & G 11 & G 12\end{array}$

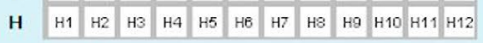

19. C6 Cytometer not connected.

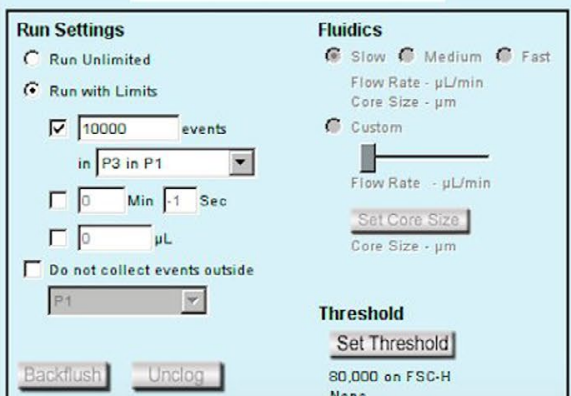

None



미 1 Rु

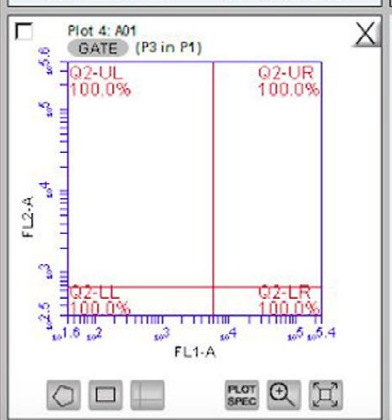

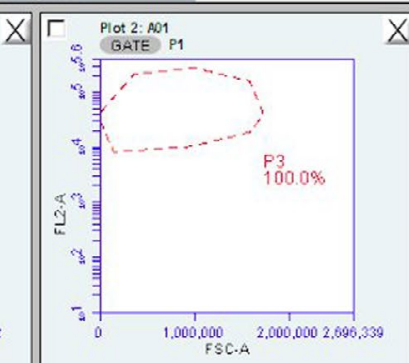

(근

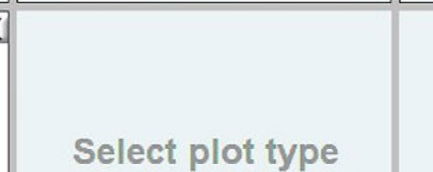

to make a new plot.

Select plot type

to make a new plot.

$M$

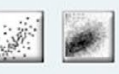

$M$

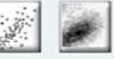

FIGURE 3 Example of template setup for the analysis of the patient sample

\section{Collect} F01 STANDARD SAMPLE

$\begin{array}{lllllllllllll}1 & 2 & 3 & 4 & 5 & 6 & 7 & 8 & 9 & 10 & 11 & 12\end{array}$

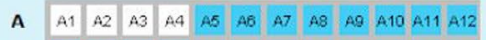

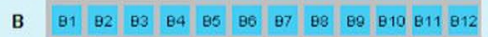

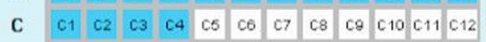

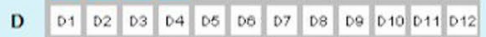

$\begin{array}{lllllllllllllll}\text { E } & E 1 & E 2 & \text { E3 } & \text { E4 } & \text { E5 } & \text { E6 } & \text { E7 } & \text { E9 } & \text { E9 E10 E11 E12 }\end{array}$

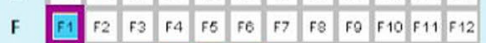

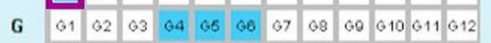

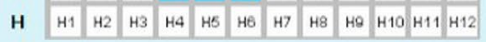

9. C6 Cytometer not connected.

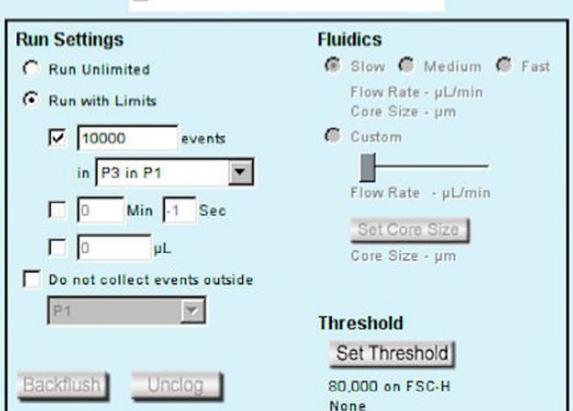

Statistics Batch Analysit:

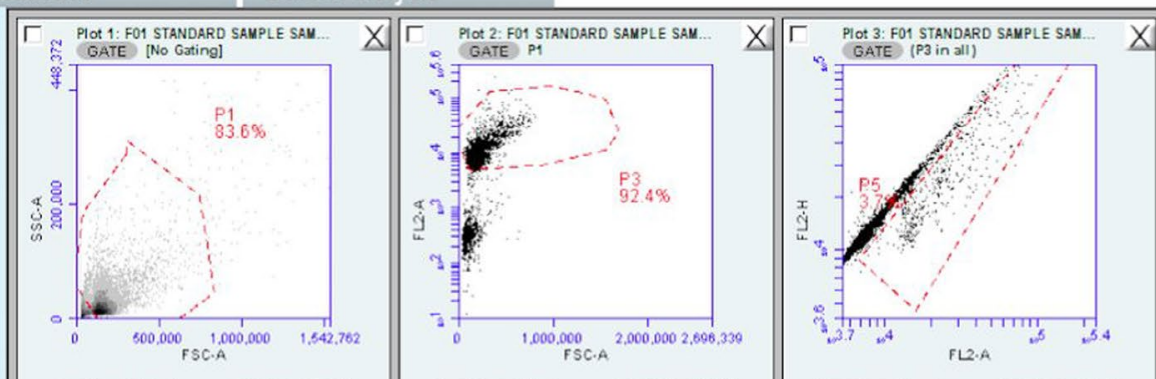

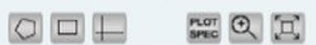

(대

ㅁ⼴ $\mathrm{Q}$ 辽
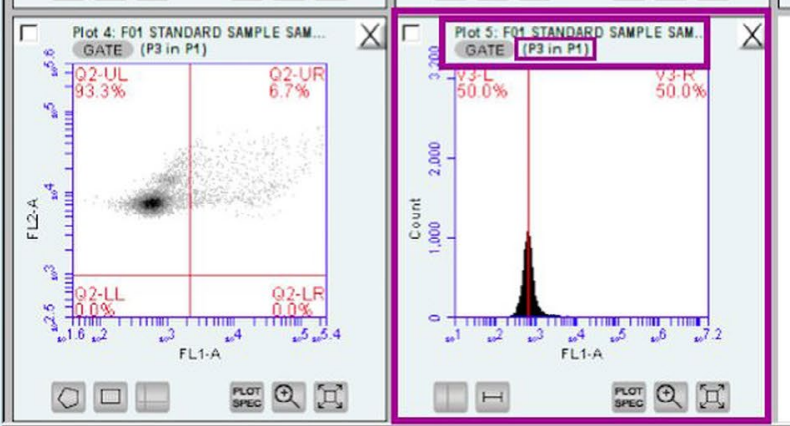

Select plot type

to make a new plot.

$\Delta$

FIGURE 4 Representation of a 'Standard sample alignment'

1. FSC-A versus SSC-A (Figure 8)

2. FSC-A versus FL2-A (Figure 9)

3. FL1-A versus FL2-A (Figure 10)

4. The first plot has no gating. The cell population is P9.

5. The gate in the second is ' $P 9$ in all events'; the population is P8.

6. The gate in the 3rd plot is 'P8 in P9' (in all events).
When the 'Virtual Gain' is applied, the FL1 axis is denoted with an asterisk. The percentage of DNA fragmentation is recorded from the FL1-A/FL2-A plot, and the file is saved (Figure 11).

To remove autofluorescence in the sample, the average \%SDF for the 'Negative' sample for each patient is calculated. This value is subtracted from the average value obtained from the patient 'Test' sample. 


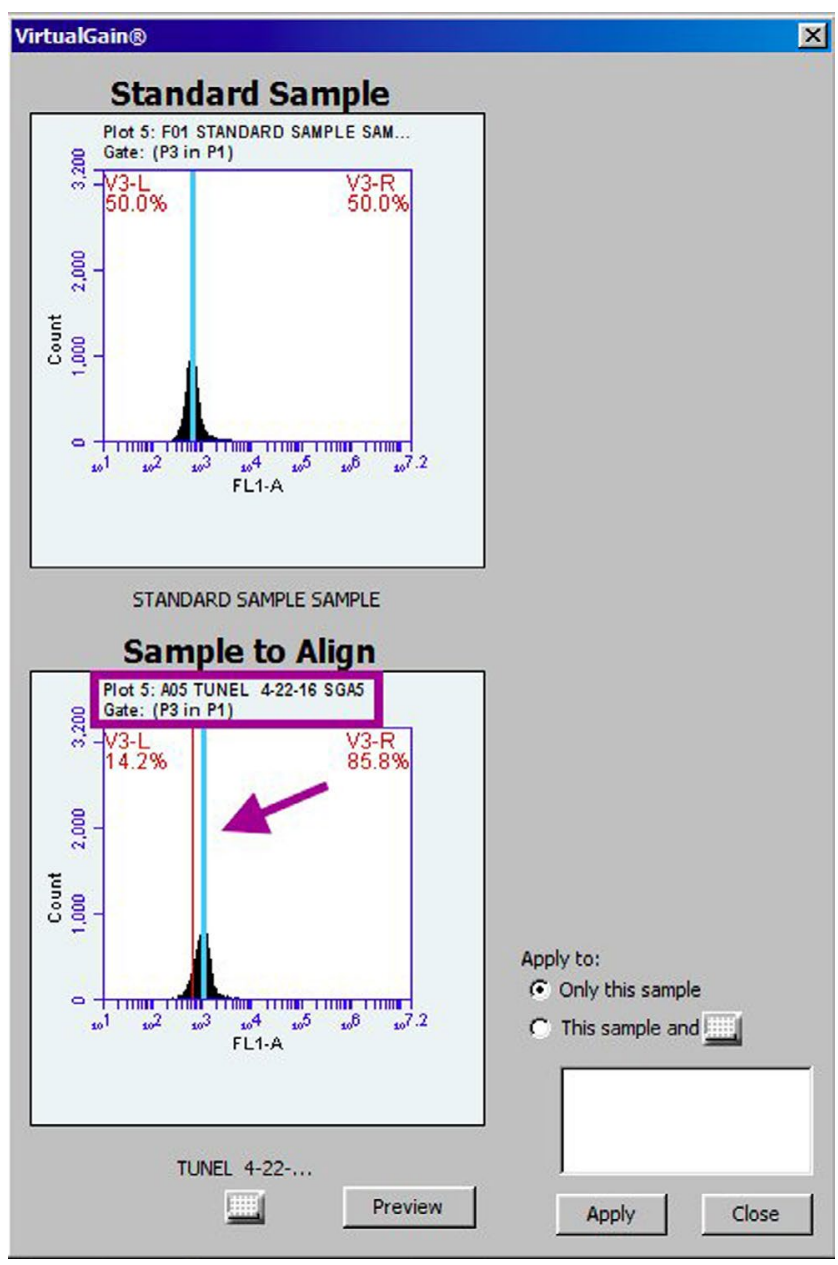

FIGURE 5 Aligning a test sample to the standard sample

The assay is correctly performed when two criteria are satisfied: 1). 'Negative' control sample should be less than $5 \%$ (Figure 12). Similarly, the percentage of cells for 'Positive' control must be greater than $40 \%$ (Figure 13).

\subsection{4 $\mid$ Reference values}

Threshold values for SDF have been established for the Accuri C6 and Accuri C6 Plus flow cytometer. SDF cut-off of $16.8 \%$, high specificity (91.6\%) and positive predictive value (91.4\%) have been shown to discriminate between infertile and fertile men (Sharma et al., 2016; Figure 14a). All controls had a DNA fragmentation below the standard cut-off value (Figure 14b).

\subsubsection{Factors that can affect the assay}

\section{Quality control}

Quality control is important and should always be done before the samples are analyzed. For C6 Accuri, performance of the instrument can be validated by measuring (a) coefficient of variation (CVs) and (b) using Levey-Jennings chart to track CVs. For validation of Accuri C6

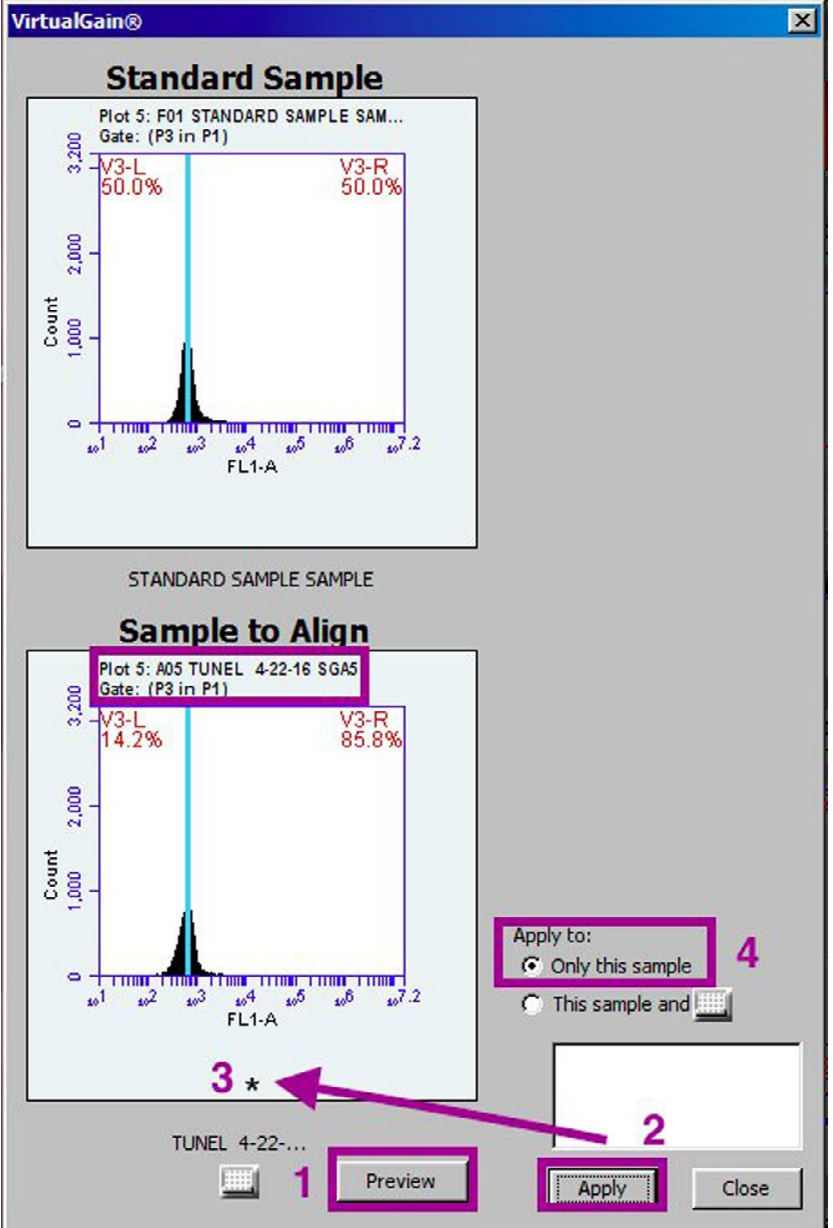

FIGURE 6 Applying the alignment to the test sample. This is indicated by an asterisk at the bottom of the histogram confirming the alignment of the sample to the standard file

flow cytometer, 8-peak beads which are $3.2 \mu \mathrm{m}$ spherical particles are used. They emit light at eight different wavelengths. One $\mathrm{mL}$ of deionised water is added to one $12 \times 75 \mathrm{~mm}$ tube labelled as ' 8 -Peak QC Beads', the contents of the vial are mixed by inverting the vial a couple of times and four drops of the 8-peak beads are added to the tube.

The 8-peak QC beads measure FL1-H, FL2-H and FL3-H channels (Figure 15). These channels correspond to the four plot locations as illustrated below:
1. FSC-H versus SSC-H
2. FL1-H versus Count
3. FL2-H versus Count
4. FL3-H versus Count.

Perform the following under the collect tab:

1. Deselect the 'time' checkbox next to 'min' and 'sec'.

2. Check he 'events' checkbox.

3. Check the number of events box entered as ' 50,000 '.

4. Select 'Ungated sample' from the drop-down menu. 


\section{Collect} A05 TUNEL 4-22-16 SGA5

$\begin{array}{lllllllllllll}1 & 2 & 3 & 4 & 5 & 6 & 7 & 8 & 9 & 10 & 11 & 12\end{array}$ A A1 A2 A3 A4 A5 AB A7 AB A9 A10 A11 A12

$\begin{array}{llllllllllllllll}\text { B } & 81 & \text { B2 } & \text { B3 } & 84 & 85 & 86 & 87 & 88 & 89 & 810 & 811 & 812\end{array}$

\begin{tabular}{llllllll|l|l|l|l|l|lll} 
C & $C 1$ & $C 2$ & $C 3$ & $C 4$ & $C 5$ & $C 6$ & $C 7$ & $C 8$ & $C 9$ & $C 10$ & $C 11$ & $C 12$
\end{tabular}

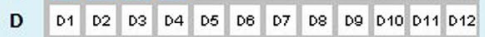

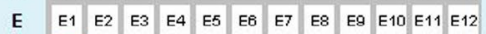

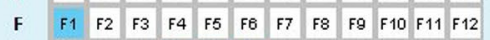

\begin{tabular}{lllllllllllllllll} 
G & $G 1$ & $G 2$ & $G 3$ & $G 4$ & $G 5$ & $G B$ & $G 7$ & $G 8$ & $G 9$ & $G 10$ & $G 11$ & $G 12$ \\
\hline
\end{tabular}

$\begin{array}{llllllllllllllllllll}\text { H } & \text { H1 } & \text { H2 } & \text { H3 } & \text { H4 } & \text { H5 } & \text { He } & \text { H7 } & \text { H8 } & \text { H9 } & \text { H10 } & \text { H11 } & \text { H12 }\end{array}$

if. C6 Cytometer not connected.

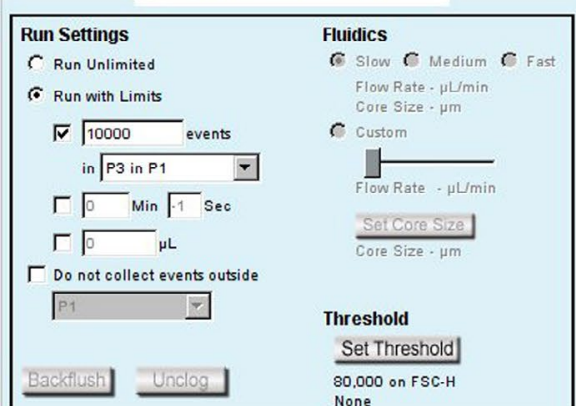

Statistics Batch Analysis
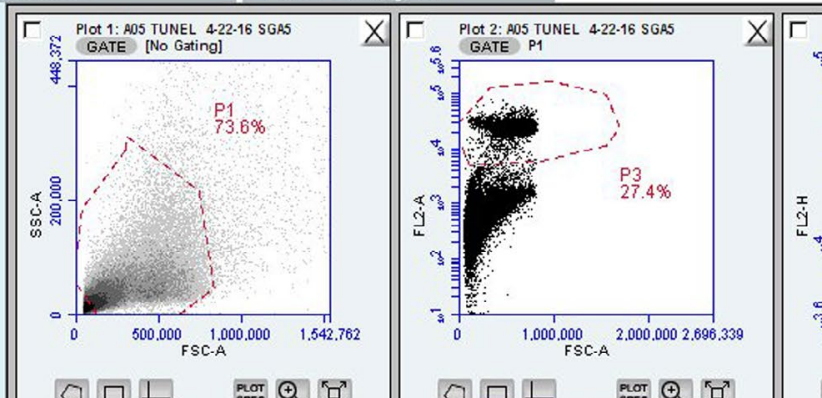

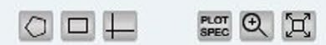

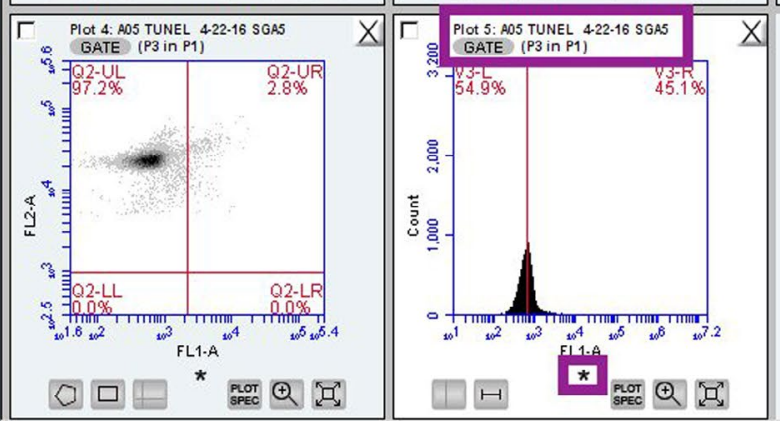

Select plot type

to make a new plot.

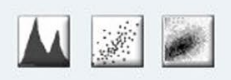

FIGURE 7 Steps showing the alignment of the well with a star saved under the histogram plot

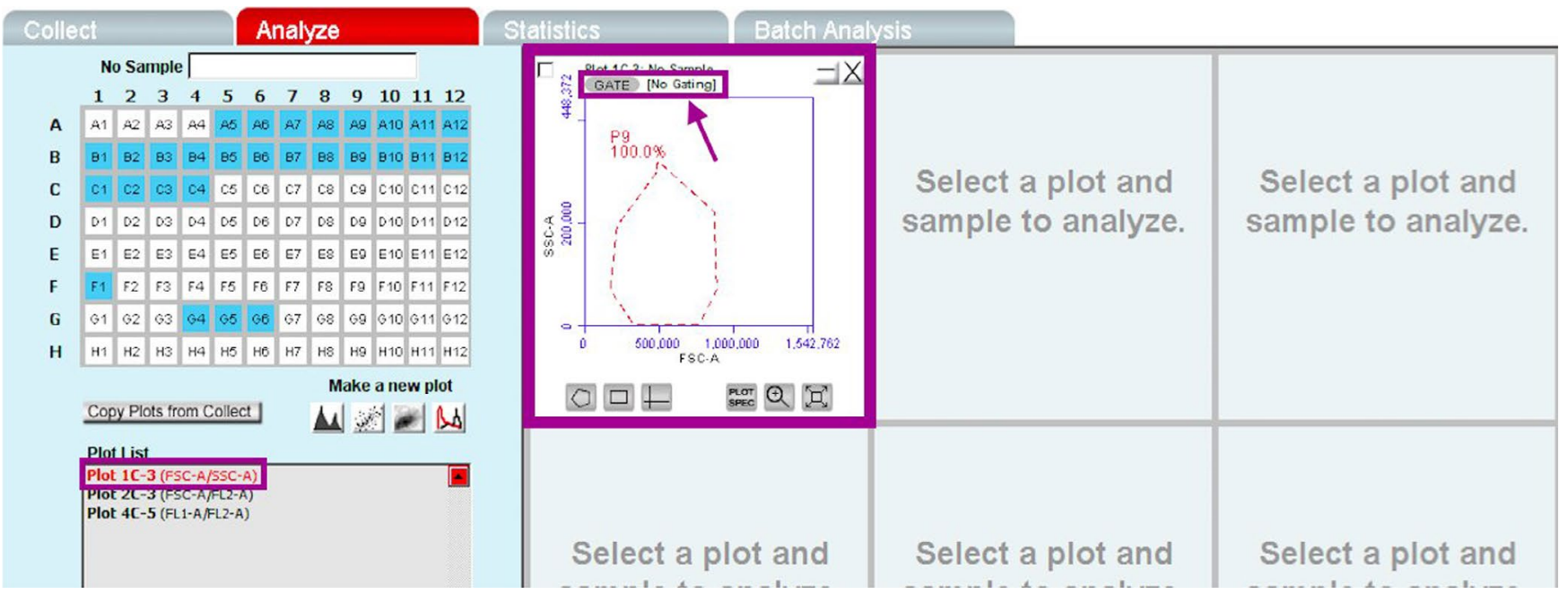

FIGURE 8 Showing the first plot with no gating

5. Check 'fluidics' speed to low.

After vortexing, run the sample to start the acquisition (Gupta et al., 2017).

To analyze the QC run, R1 gate is adjusted such that $75 \%$ to $85 \%$ of all events are contained in the R1 gate.

1. Include the main bead population, that is all singlets. This is done in the first plot, FSC-H versus. SSC-H plot (top-left), by adjusting the border of the R1 gate

2. Exclude all the light-grey dots (doublets) that are outside the dark black (singlet) population.
3. Gate FL1-H, FL2-H and FL3-H histograms on R1 and measure the $\mathrm{CV}$ of the brightest peak in the three histograms.

4. To meet the validation criteria, each peak must have $<5 \% \mathrm{CV}$. The data can also be displayed in Levey-Jennings plot.

Similarly, for the C6 Plus cytometer, QC can be performed using the BD CS\&T RUO beads to check and monitor the instrument's performance. The CS\&T RUO beads have a known median fluorescence intensity (MFI) and distribution ( $\mathrm{rCV}$ ), and allow to characterise, track and report measurements made by the cytometer. The software sets regions around the dim beads and the mid + bright beads (Sharma et al., 2019). 


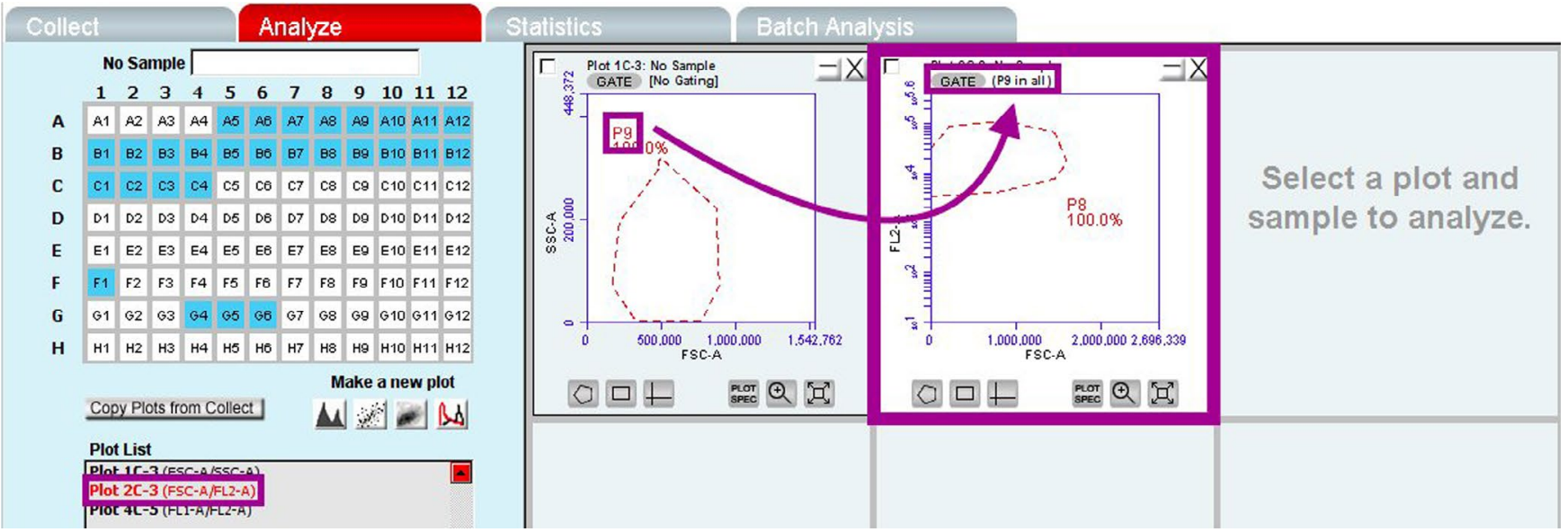

FIGURE 9 Showing the second plot gate with P9 in all events

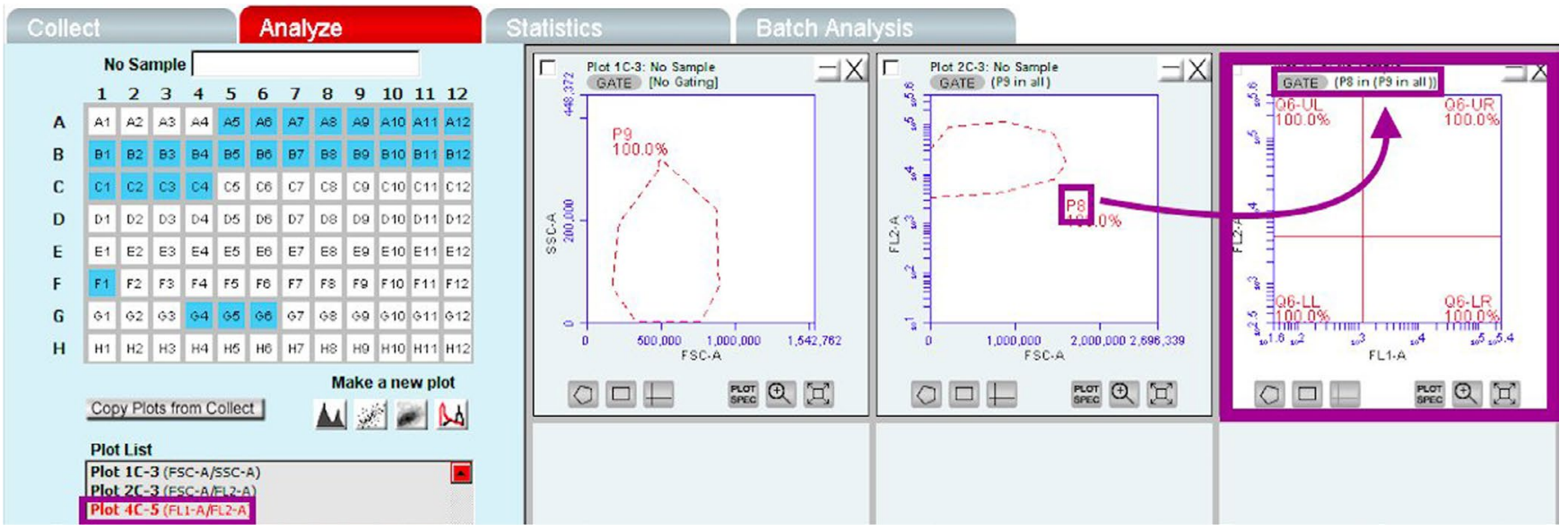

FIGURE 10 Third plot gate showing P8 in P9 in all events

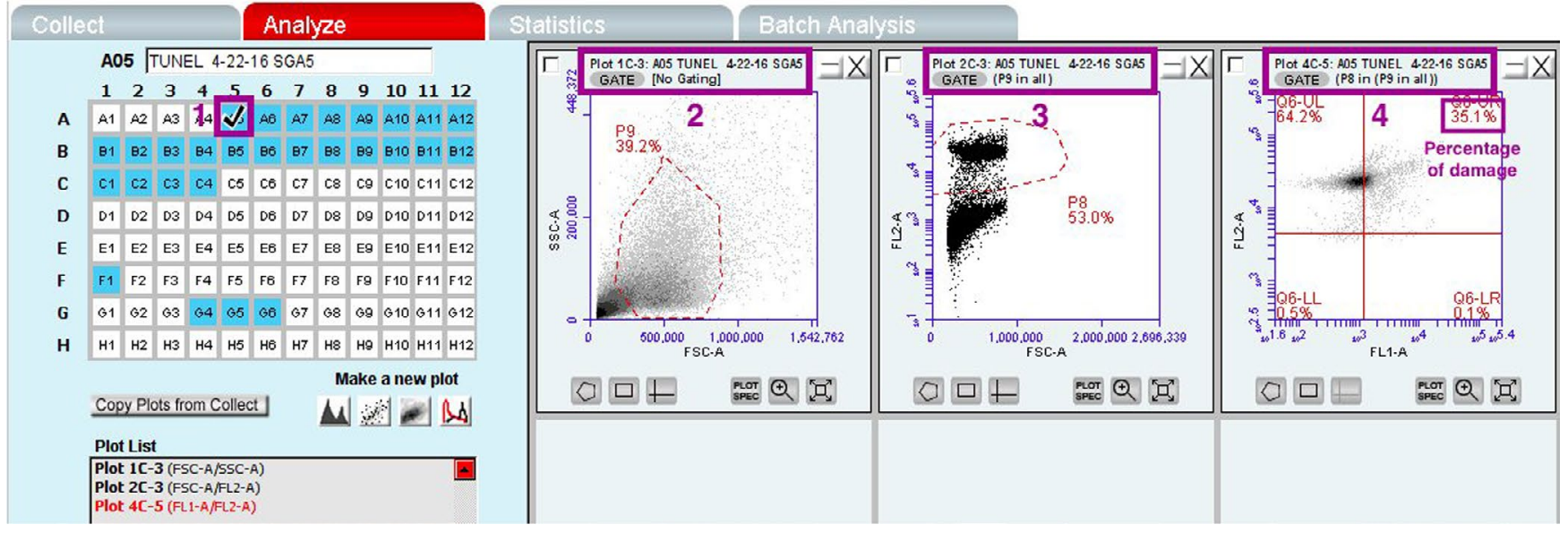

FIGURE 11 Plot in the analyzed mode showing percentage of DNA damage

The system measures the brightness and distribution of the bright beads and compares the results to expected values. Instrument sensitivity is also calculated. In addition, the compensation values are updated based on the CS\&T RUO bead results. When the QC test is complete, a Pass or Fail result is displayed. The
QC is run as per the manufacturer's instructions and the reports can be tracked using the Levey-Jennings plots. The graphs in the report show random errors or shifts and trends in the data for each parameter and help diagnose possible problems with the system. The graphs show the bright bead median values, percentage $\mathrm{rCV}$ and 




FIGURE 12 Representative plot of 'Negative kit control'

sensitivity with standard deviations for FSC, SSC, FL1, FL2, FL3 and FL4. The QC Report table displays the values and Pass/Fail result for each parameter. If any of the results for an individual parameter fails, the failed parameter result appears in red and the overall instrument QC result fails. The samples should be run only once the QC report appears as Pass.

Viscous or oligozoospermic samples, accessibility of stains to DNA, method of sperm preparation, dead cells, number of cells examined and the inter- and intra-observer as well as inter- and intra-assay variation can influence the assay results. It is important that the staining step and incubation at $37^{\circ} \mathrm{C}$ is performed strictly for $1 \mathrm{~h}$, as longer incubation times will overstain the samples. The samples must be run within $3 \mathrm{~h}$ after staining and overnight storage of stained cells must be avoided. Concentration of the fixative, storage time of fixed samples, fluorochrome used and methodology for analyzing the data can significantly affect SDF (Muratori et al., 2010). The alignment of the samples with the internal 'Standard' sample must be carefully done in the 'Collect' tab along with the gating strategies applied in the Collect tab. This is necessary to avoid large variations in the final values of DNA fragmentation.

\subsection{6 | Benchtop cytometry}

Both the BD Accuri C6 and C6 Plus Systems are non-pressurised systems. They include an all-in-one desktop workstation running BD Accuri C6 or C6 Plus software. The system also includes the 8-Peak beads for C6 and CS\&T RUO beads for C6 Plus instrument Quality Control (Sharma et al., 2019).

The optical components for both flow cytometers consist of the blue laser $(488 \mathrm{~nm})$ and the red laser $(640 \mathrm{~nm})$. The optical assembly consists of 4 filters: 1) FL1 (533/30 nm), 2) FL2 (585/40 nm), 3) FL3 > 670 LP nm and 4) FL4 (675/25 nm) filters. For TUNEL assay, the FL1 green channel for fluorescence isothiocyanate (FITC) stain and the red channel $640 \mathrm{~nm}$ can be used for the propidium iodide staining. In the centre of the four filters is the flow cell and consists of a capillary where the laser intersects the sample stream. The C6 Plus Accuri flow cytometer also has an optional barcode reader that can be attached to a USB port on the computer. The two-laser, six-parameter flow cytometer is composed of fluidics, optics and electronics systems. The fluidics system consists of peristaltic pumps providing a non-pressurised, 'push/pull' fluid system. To maximize light collection, optical detectors are clustered around the flow 


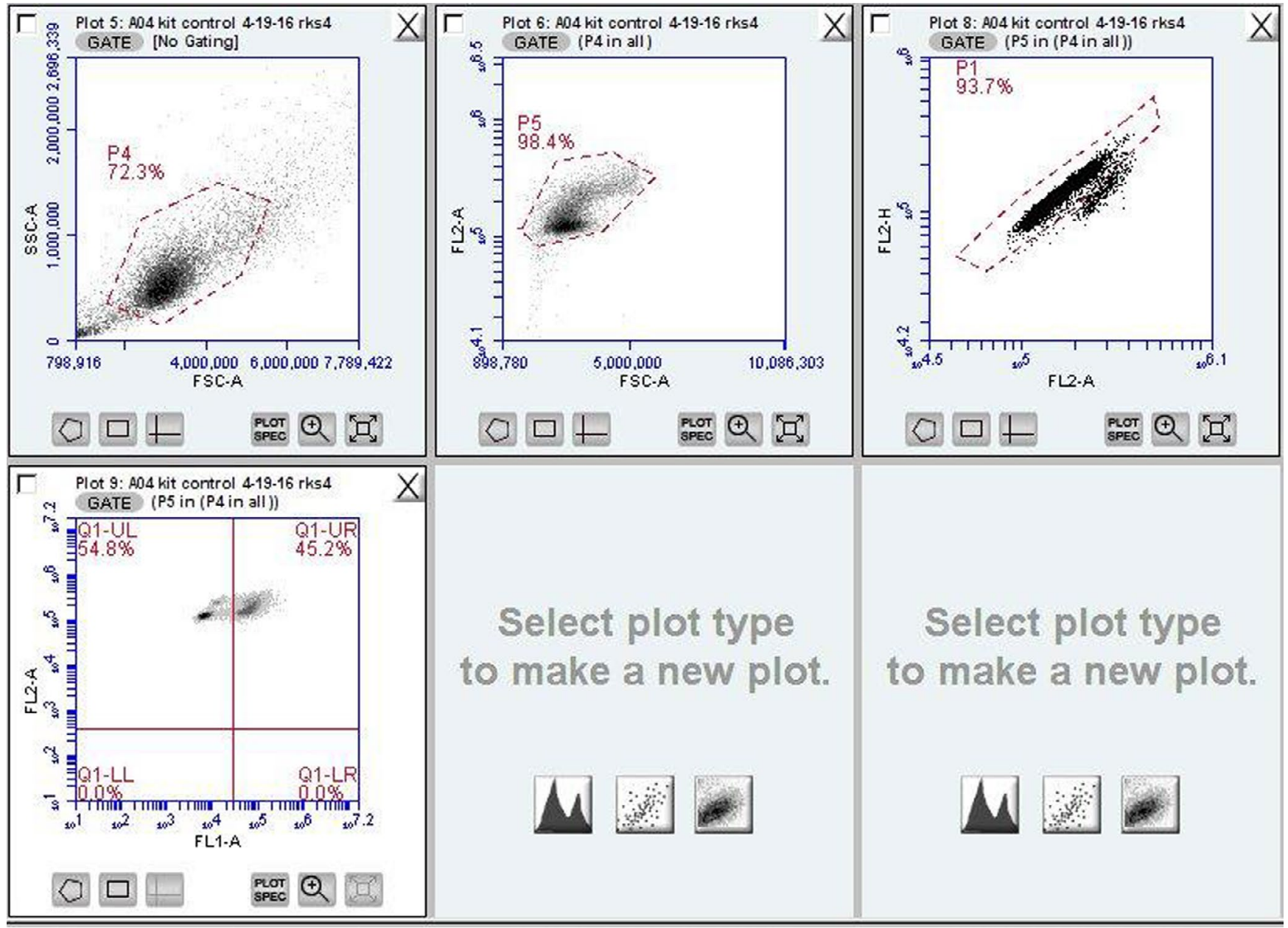

FIGURE 13 Representative plot of 'Positive kit control'

(a)

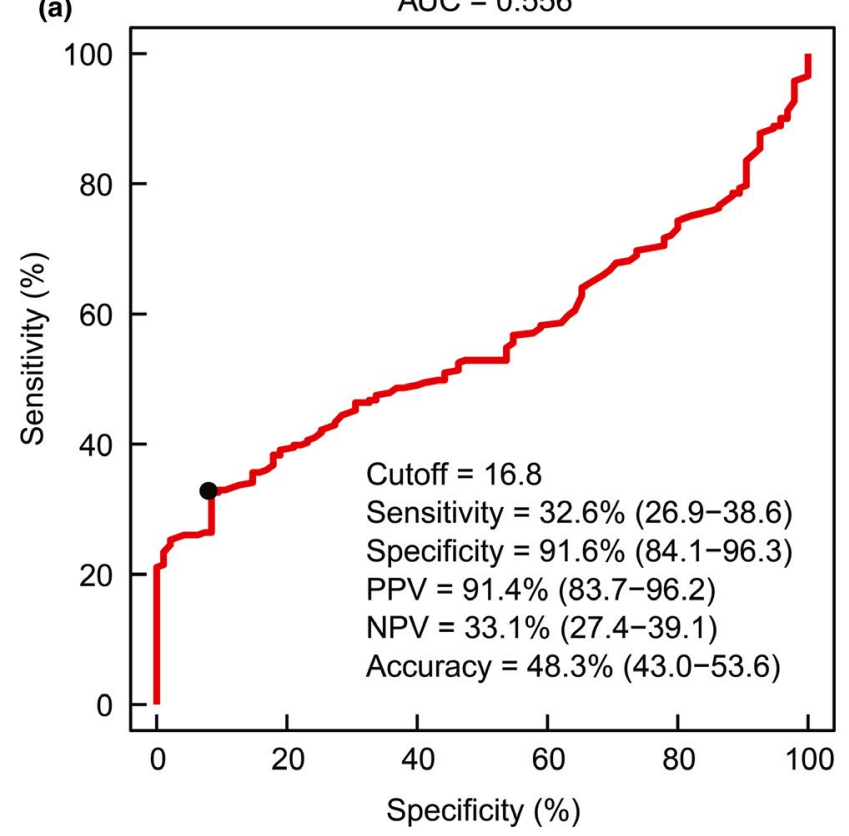

(b)



FIGURE 14 Receiver operator characteristic (ROC) curve showing (a) TUNEL assay cut-off and the area under the curve. Values within the parentheses represent the $95 \%$ confidence interval and (b) distribution of TUNEL test values between controls and infertile men 




FIGURE 15 8-peak quality control beads as seen after analysis in software; CV of the brightest peak (M3, M6, M9) is measured

cell. The electronics system provides up to 7 decades of dynamic range, allowing for fixed detector voltages.

Both the $\mathrm{C} 6$ and $\mathrm{C} 6$ Plus have the fluidic components comprised of the sheath bottle, waste bottle, detergent solution bottle and the BD FACS clean solution or the yellow bottle. Both cytometers include the in-line sheath filter, the sheath pump, waste pump and the sample injection probe (SIP). Both flow cytometers have been standardized for method comparison, precision and accuracy. Both C6 Plus versus $\mathrm{C} 6$ flow cytometer have been compared for concordance coefficient correlation, precision, accuracy, cut-off, sensitivity and specificity in using the unadjusted and adjusted settings. Similarly, the inter- and intra-assay variation and precision of the two instruments has also been compared (Sharma et al., 2019). Passing-Bablok regression analysis was used to test the concordance and methods comparison between the two instruments (Figure 16). Spermatozoa from patients, donors, internal positive and negative controls for spermatozoa were compared on the two instruments by generating Bland-Altman plots.

A highly significant ( $r=.992 ; 95 \% \mathrm{Cl}$ : 0.982-0.997; $p<.0001)$ correlation was seen between SDF values acquired from the adjusted workspace in the C6 Plus and standardised workspace for C6 flow cytometer (Sharma et al., 2019). Much smaller differences were seen between C6 Plus adjusted and the C6 standard method, which are obvious from the Bland-Altman plots (Figure 17). A strong concordance and high precision (98\%), accuracy $>99 \%$ was seen between the two flow cytometers. Similarly, a strong agreement between inter-observers was reported on the C6 flow cytometer (rank correlation coefficient $=0.922 ; p<.0001$ ) and $95 \% \mathrm{Cl}$ of 0.83-0.97 (Sharma et al., 2019). Unadjusted C6 Plus had low sensitivity (94.4\%) and specificity $(80.0 \%)$ and an area under curve (AUC) of 0.90. The SDF cut-off was significantly lower (7.5\%) than the established cut-off of $17.0 \%$ (Figure 18a). After adjusting the settings, the two instruments could predict TUNEL results with similar accuracy (Figure 18b).

The inter-observer variability on C6 Plus was small and highly correlated $(r=.993 ; p<.0001)$ with $95 \% \mathrm{Cl}$ of 0.985-0.997. A high intra-observer agreement was seen on $\mathrm{C} 6$ as was the inter-observer agreement on the C6 flow cytometer for the two observers (Sharma et al., 2019).

Many kits combine the TUNEL assay with PI to exclude apoptotic nuclear bodies in the semen (Marchiani et al., 2014). Apoptotic bodies interfere with the TUNEL analysis. Spermatozoa can be categorized into two distinct populations using $\mathrm{PI}$ staining, that is PI-dimmer population reflects dead spermatozoa and PI-brighter population consists of spermatozoa with variable fractions of live and dead spermatozoa (Marchiani et al., 2014; Muratori et al., 2008). The diagnostic power of 

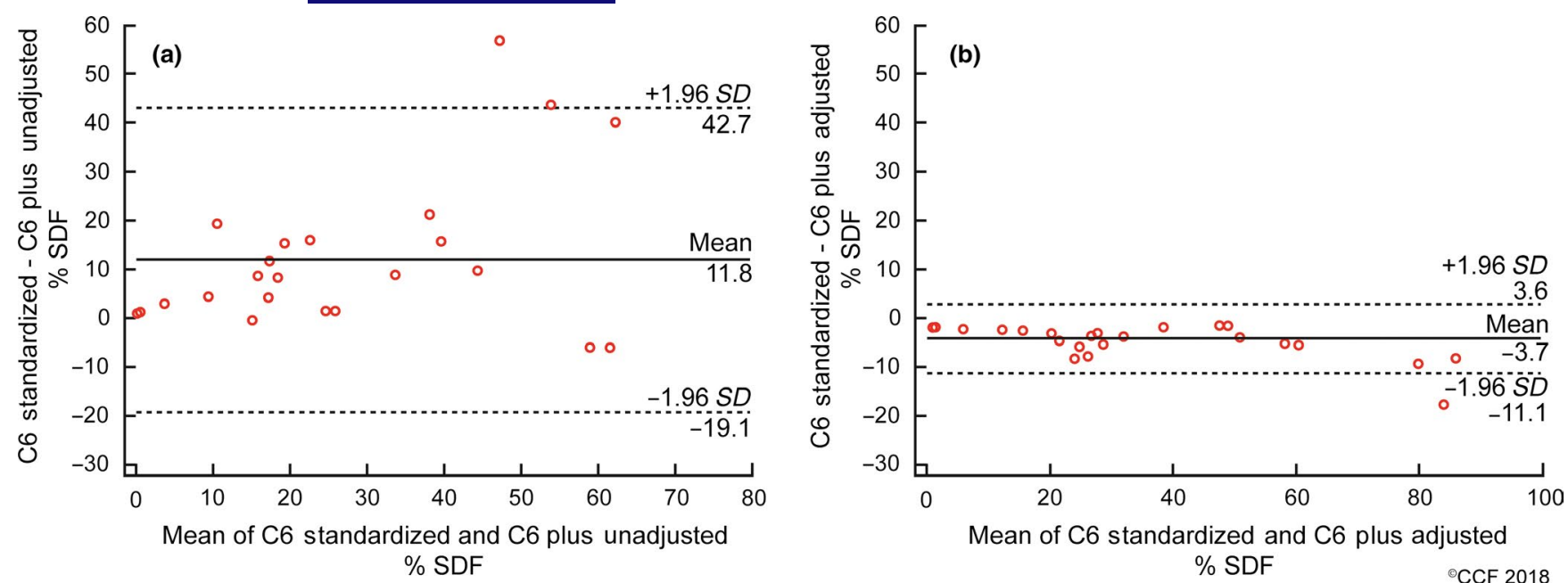

FIGURE 16 Passing-Bablok regression analysis showing (a) unadjusted C6 Plus versus C6 standardized and (b) adjusted C6 Plus versus C6 standardized. The wider deviation of the values from one another can clearly be seen

the TUNEL test is increased by including PI. The clinical utility of PI inclusion is that SDF in the bright population is able to predict male fertility independently from conventional semen parameters and age. High SDF in this subpopulation can better discriminate infertile patients and fertile controls than when SDF is measured in the total sperm population, that is brighter and the dimmer population (Muratori et al., 2015).

\section{3 | Common laboratory protocols between TUNEL and flow cytometry}

It is important to standardize the TUNEL protocol using flow cytometer, both in terms of the instrumentation and the kit that is used to stain the cells. Both direct kits such as APO-DIRECT ${ }^{\mathrm{TM}}$ kit (BD Pharmingen) and the In Situ Cell Death Detection, Fluorescein kit (Roche Diagnostics) use a direct labelling system such as fluorescein isothiocyanate-dUTP. Indirect kits such as Apo-BrdU In Situ DNA Fragmentation kit (BioVision) use an antibody-based labelling system.

In the indirect antibody-based kit, BrdUTP is used to label the DNA. BrdUTP binds to the 3'-OH terminals of the DNA strand breaks and TDT. The antibodies to the BrdUTP are tagged to the fluorescein molecule that is detected in the FL1 channel and propidium iodide fluorescence is recorded in the FL3 channel (Anzar, He, Buhr, Kroetsch, \& Pauls, 2002; Ribeiro, Muratori, De Geyter, \& De Geyter, 2017; Ribeiro et al., 2013).

\subsection{Challenges in using TUNEL assay to measure DNA integrity}

Commercially available kits are commonly used for measuring DNA breaks. The inclusion of PI staining in TUNEL flow cytometry makes the TUNEL test a gold standard for SDF. However, the threshold values vary greatly among different labs from 20\% (Sergerie,
Laforest, Bujan, Bissonnette, \& Bleau, 2005; Sharma et al., 2010) to $35 \%$ (Domínguez-Fandos, Camejo, Ballescà, \& Oliva, 2007; Sepaniak et al., 2006). This is attributed to the large differences in the methodologies.

Ribeiro et al., 2017 demonstrated an underestimation in the SDF by TUNEL test with the indirect method using fluorescent antibody (BrdUTP/FITC-anti-BrdUTP) compared to direct labelling systems. This was especially true in the PI-dimmer population which consisted of dead spermatozoa in the fresh semen sample before fixation (Ribeiro et al., 2017). The PI-brighter population strongly stains live and dead spermatozoa (Marchiani et al., 2014). Indirect antibody-based (BrdUTP/fluorescein-anti-BrdUTP) kits underestimate SDF due to steric hindrance, and therefore, these kits are not recommended to be used to measure DNA damage in semen. The differences in SDF between the direct and indirect method ranged from $19.2 \%$ to $85.3 \%$. Indirect labelling stained a lower number of cells $(40.1 \%$ [23.6\%, 58.2\%]) compared to $65.7 \%$ [36.5\%, 90.9\%] $(n=10, p<.05)$ staining with the direct labelling (Ribeiro et al., 2017).

\section{5 | Clinical implication of TUNEL assay in assessing male infertility}

Sperm DNA fragmentation is an important tool in evaluating male fertility. The clinical utility of SDF is valuable in infertile men with clinical varicocele pre- and post-varicocelectomy, obesity, history of chemotherapy or radiation exposure, associated with high SDF and recurrent pregnancy loss (Agarwal, Cho, Majzoub, \& Esteves, 2017; Agarwal, Majzoub, et al., 2016; Baskaran et al., 2019; Majzoub, Agarwal, \& Esteves, 2017). Some of the important clinical implications of using TUNEL assay in assessing male infertility are briefly described below: 



FIG URE 17 Bland-Altman plots for (a) unadjusted C6 Plus versus C6 standardized and (b) adjusted C6 Plus versus C6 standardized

(a)



(b)



FIGURE 18 Receiver operating characteristic (ROC) curve showing sensitivity, specificity and cut-off for C6 Plus in (a) unadjusted SDF and (b) after adjustment with the standard C6 flow cytometer

\subsection{1 | Ejaculatory Abstinence}

Prolonged ejaculatory abstinence increases SDF (Agarwal, Gupta, Du Plessis et al., 2016). Lower SDF was seen with shorter ejaculatory abstinence periods. When ejaculatory abstinence was categorized into short ( $<1$ day), recommended ( $2-7$ days) and long ( $>7$ days), SDF increased progressively. These findings validate that the direct relationship between ejaculatory abstinence and DNA damage not only in men with normozoospermia but in men with infertility problems (Agarwal,
Gupta, Du Plessis, et al., 2016; Borges, Braga, Zanetti, laconelli, \& Setti, 2019; Gosálvez, González-Martínez, López-Fernández, Fernández, \& Sánchez-Martín, 2011; Gosálvez et al., 2011). The WHO 2010 guideline still recommends 2-7 days abstinence (WHO, 2010).

\subsection{2 | Varicocele}

Poor sperm quality in varicocele patients is associated with oxidative stress (Hendin, Kolettis, Sharma, Thomas, \& Agarwal, 1999; 
Pasqualotto et al., 2008). Increased sperm DNA fragmentation index (DFI) seen in varicocele patients is largely due to ROS mediated OS (Baskaran et al., 2019; Esteves, 2019; Smith et al., 2006). Elevated serum FSH level, higher oxidative reduction potential (ORP) and DFI values are seen in infertile men with varicocele compared to fertile controls. Furthermore, ORP and DFI was inversely related with semen parameters (Tanaka et al., 2020). Patients with grade $2 / 3$ and normal conventional semen parameters (grade $\mathrm{C}$ recommendation) and patients with grade 1 varicocele and borderline/abnormal conventional semen parameter results (grade $C$ recommendation) might be candidates for SDF testing (Esteves, 2019; Roaque and Esteves). In a recent report, lower amounts of global sperm DNA methylation were reported in men with varicocele $(49.7 \% \pm 20.7 \%)$ compared to controls $(64.7 \% \pm 17.1 \%)$. SDF was negatively correlated with sperm motility and a positively with sperm morphology and telomere length (Nguyen, Trieu, Tran, \& Luong, 2019; Santana et al., 2019). These findings suggest genomic instability. Understanding molecular mechanisms involved in pathophysiology of varicocele-related infertility might help in selection of surgical candidates for varicocele correction. The effect of varicocelectomy on sperm DNA damage has been extensively studied (Cho, Esteves, \& Agarwal, 2019; Nguyen et al., 2019; Roque \& Esteves, 2018; Santana et al., 2019). In a retrospective study consisting of 511 patients from 9 prospective and 3 retrospective studies, reduction in SDF following varicocelectomy was seen (Lara-Cerrillo et al., 2020; Roaque \& Esteves, 2018; Zini \& Dohle, 2011).

\subsection{3 | Natural pregnancy}

Improved chances of natural pregnancy are found in couples with lower SDF values as determined by both TUNEL and SCSA (Malić Vončina et al., 2016). Similarly, TUNEL has been shown to better predict natural pregnancy with high sensitivity and specificity (Wiweko B \& Utami P., 2017).

In intrauterine insemination (IUI), none of the women achieved a pregnancy if the samples had $>12 \%$ SDF measured by TUNEL assay (Duran, 2002).

\subsection{4 | In vitro fertilization}

A modest relationship between sperm DNA damage and pregnancy rates with IVF was reported in two systematic reviews (Collins et al., 2008; Zini \& Sigman, 2009). The first review examined 9 IVF studies ( 6 using TUNEL and 3 SCSA) and reported lower pregnancy rates in patients with a high SDF (combined OR of $1.57 ; 95 \% \mathrm{Cl}$, 1.18-2.07; $p<.05$ ). The other review had 553 patients who underwent conventional IVF, and the data showed a statistically significant association between SDF (measured by TUNEL, SCSA and Comet) and pregnancy rate (OR of 1.27; 95\% Cl, 1.05-1.52; $p=.01$ ) (Osman et al., 2015).

\subsubsection{SDF and risk of pregnancy loss after ART}

High DNA damage was associated with a significant increase in pregnancy loss in patients compared to those with low DNA damage [risk ratio $(\mathrm{RR})=2.16(95 \% \mathrm{Cl}, 1.54-3.03 ; p<.001)$ ] (Robinson et al., 2012). Lower SDF levels have been reported with use of testicular spermatozoa $(4.8 \% \pm 3.6 \%)$ compared to ejaculated spermatozoa $(23.6 \% \pm 5.1 \% ; p<.001)$, and higher pregnancy rates were reported in testicular spermatozoa and ICSI $(44.4 \%$ versus 6\%; $p$.05) (Greco et al., 2005). Another meta-analysis analysed 998 couples and showed that couples whose male partners had low SDF achieved higher live birth rates after IVF (Osman et al., 2015).

Use of SDF testing has been recommended in the following cases: (a) patients with recurrent failures in IVF and ICSI, (b) use of testicular spermatozoa in men with oligozoospermia and (c) recurrent IVF failure (Agarwal et al., 2017; Esteves, 2019).

\section{6 | CONCLUSION}

Sperm chromatin structure assay is a proprietary technique that cannot be conducted in all laboratories. TUNEL is well standardised by independent laboratories for inter- and intra-observer variability and can be performed using a readily available TUNEL detection kit. TUNEL appears to be the most promising method for measuring SDF. It can directly examine the sperm DNA strand breaks by measuring 10,000 cells using flow cytometry. It is therefore a very robust technique. Existing protocols need to be standardized and validated before adopting them into prospective studies or routinely in a clinical setting. The antibody-based system greatly underestimates SDF, especially in infertile patients with reduced sperm motility. BrdUTP/fluorescein-anti-BrdUTP kits should not be recommended to measure DNA damage in semen. It is imperative that the methodology is standardized across andrology laboratories worldwide to further reduce the variability, whether it is the choice of staining kits, instrumentation or inter- and intra-observer variability.

\section{7 | TAKE-HOME MESSAGES}

- TUNEL assay combined with flow cytometry is a promising method for quantification of SDF.

- Measuring SDF with TUNEL by flow cytometry is robust and can measure 10,000 cells very rapidly.

- Direct kits using fluorescein-dUTP are commercially available for the detection of SDF. 
- Indirect antibody-based (BrdUTP/fluorescein-anti-BrdUTP) kits underestimate SDF due to steric hindrance.

\section{ORCID \\ Rakesh Sharma (iD https://orcid.org/0000-0002-9664-6978 Concetta lovine (iD https://orcid.org/0000-0002-9636-5842 Ashok Agarwal iD https://orcid.org/0000-0003-0585-1026 Ralf Henkel iD https://orcid.org/0000-0003-1128-2982}

\section{REFERENCES}

Abd-Elmoaty, M. A., Saleh, R., Sharma, R., \& Agarwal, A. (2010). Increased levels of oxidants and reduced antioxidants in semen of infertile men with varicocele. Fertility and Sterility, 94(4), 1531-1534. https://doi. org/10.1016/j.fertnstert.2009.12.039

Agarwal, A., Cho, C.-L., Majzoub, A., \& Esteves, S. C. (2017). The Society for translational medicine: Clinical practice guidelines for sperm DNA fragmentation testing in male infertility. Translational Andrology and Urology, 6(S4), S720-S733. https://doi.org/10.21037 /tau.2017.08.06

Agarwal, A., Gupta, S., Du Plessis, S., Sharma, R., Esteves, S. C., Cirenza, C., ... Sabanegh, E. (2016). Abstinence time and its impact on basic and advanced semen parameters. Urology, 94, 102-110. https://doi. org/10.1016/j.urology.2016.03.059

Agarwal, A., Gupta, S., \& Sharma, R. (2016). Measurement of DNA fragmentation in spermatozoa by TUNEL assay using bench top flow cytometer. In A. Agarwal, S. Gupta, \& R. K. Sharma (Eds.), Andrological evaluation of male infertility: A laboratory guide (pp. 181-203). New York: Springer.

Agarwal, A., Majzoub, A., Esteves, S. C., Ko, E., Ramasamy, R., \& Zini, A. (2016). Clinical utility of sperm DNA fragmentation testing: Practice recommendations based on clinical scenarios. Translational Andrology and Urology, 5(6), 935-950. https://doi.org/10.21037/ tau.2016.10.03

Agarwal, A., \& Said, T. M. (2003). Role of sperm chromatin abnormalities and DNA damage in male infertility. Human Reproduction Update, 9(4), 331-345. https://doi.org/10.1093/humupd/dmg027

Agarwal, A., Virk, G., Ong, C., \& du Plessis, S. S. (2014). Effect of oxidative stress on male reproduction. The World Journal of Men's Health, 32(1), 1. https://doi.org/10.5534/wjmh.2014.32.1.1

Aitken, R. J., \& De luliis, G. N. (2010). On the possible origins of DNA damage in human spermatozoa. Molecular Human Reproduction, 16(1), 3-13.

Alvarez, J. G. (2005). The predictive value of sperm chromatin structure assay. Human Reproduction, 20(8), 2365-2367. https://doi. org/10.1093/humrep/dei014

Anzar, M., He, L., Buhr, M. M., Kroetsch, T. G., \& Pauls, K. P. (2002). Sperm apoptosis in fresh and cryopreserved bull semen detected by flow cytometry and its relationship with fertility. Biology of Reproduction, 66(2), 354-360.

Baskaran, S., Agarwal, A., Panner Selvam, M. K., Finelli, R., Robert, K. A., lovine, C., ... Henkel, R. (2019). Tracking research trends and hotspots in sperm DNA fragmentation testing for the evaluation of male infertility: A scientometric analysis. Reproductive Biology and Endocrinology, 17(1), 110. https://doi.org/10.1186/s12958-019-0550-3

Benchaib, M., Braun, V., Lornage, J., Hadj, S., Salle, B., Lejeune, H., \& Guérin, J. F. (2003). Sperm DNA fragmentation decreases the pregnancy rate in an assisted reproductive technique. Human Reproduction, 18(5), 1023-1028. https://doi.org/10.1093/humrep/ deg228

Borges, E. Jr, Braga, D. P. A. F., Zanetti, B. F., laconelli, A. Jr, \& Setti, A. S. (2019). Revisiting the impact of ejaculatory abstinence on semen quality and intracytoplasmic sperm injection outcomes. Andrology, 7(2), 213-219. https://doi.org/10.1111/andr.12572
Bungum, M. (2012). Sperm DNA integrity assessment: A new tool in diagnosis and treatment of fertility. Obstet Gynecol Int, 2012, 531042. https://doi.org/10.1155/2012/531042

Bungum, M., Humaidan, P., Axmon, A., Spano, M., Bungum, L., Erenpreiss, J., \& Giwercman, A. (2007). Sperm DNA integrity assessment in prediction of assisted reproduction technology outcome. Human Reproduction, 22(1), 174-179. https://doi.org/10.1093/humrep/ del326

Bungum, M., Humaidan, P., Spano, M., Jepson, K., Bungum, L., \& Giwercman, A. (2004). The predictive value of sperm chromatin structure assay (SCSA) parameters for the outcome of intrauterine insemination, IVF and ICSI. Human Reproduction, 19(6), 1401-1408.

Calogero, A. E., Burrello, N., De Palma, A., Barone, N., \& Vicari, E. (2003). Sperm aneuploidy in infertile men. Reprod Biomed Online, 6(3), 310317. https://doi.org/10.1016/S1472-6483(10)61850-0

Calogero, A. E., De Palma, A., Grazioso, C., Barone, N., Burrello, N., Palermo, I., ... D'Agata, R. (2001). High sperm aneuploidy rate in unselected infertile patients and its relationship with intracytoplasmic sperm injection outcome. Human Reproduction, 16(7), 1433-1439. https://doi.org/10.1093/humrep/16.7.1433

Carrell, D. T. (2008). The clinical implementation of sperm chromosome aneuploidy testing: Pitfalls and promises. Journal of Andrology, 29(2), 124-133. https://doi.org/10.2164/jandrol.107.003699

Castilla, J. A., Zamora, S., Gonzalvo, M. C., Luna Del Castillo, J. D., RoldanNofuentes, J. A., Clavero, A., ... Martínez, L. (2010). Sperm chromatin structure assay and classical semen parameters: Systematic review. Reproductive BioMedicine Online, 20(1), 114-124. https://doi. org/10.1016/j.rbmo.2009.10.024

Cho, C. L., \& Agarwal, A. (2017). Role of sperm DNA fragmentation in male factor infertility: A systematic review. Arab Journal of Urology, 16(1), 21-34. https://doi.org/10.1016/j.aju.2017.11.002

Cho, C. L., Esteves, S. C., \& Agarwal, A. (2019). Indications and outcomes of varicocele repair. Panminerva Medica, 61(2), 152-163. https://doi. org/10.23736/S0031-0808.18.03528-0

Cissen, M., Van Wely, M., Scholten, I., Mansell, S., De Bruin, J. P., Mol, B. W., ... Hamer, G. (2016). Measuring sperm DNA fragmentation and clinical outcomes of medically assisted reproduction: A systematic review and meta analysis. PLoS One, 11(11), e0165125. https://doi. org/10.1371/journal.pone.0165125

Collins, J. A., Barnhart, K. T., \& Schlegel, P. N. (2008). Do sperm DNA integrity tests predict pregnancy with in vitro fertilization? Fertility and Sterility, 89(4), 823-831. https://doi.org/10.1016/j.fertn stert.2007.04.055

Cortés-Gutiérrez, E. I., Fernández, J. L., Dávila-Rodríguez, M. I., LópezFernández, C., \& Gosálvez, J. (2017). Two-tailed comet assay (2T-Comet): Simultaneous detection of DNA single and double strand breaks. Methods in Molecular Biology, 1560, 285-293.

Cui, Z. L., Zheng, D. Z., Liu, Y. H., Chen, L. Y., Lin, D. H., \& Lan, F. H. (2015). Diagnostic accuracies of the TUNEL, SCD, and Comet based sperm DNA fragmentation assays for male infertility: A meta-analysis study. Clinical Laboratory, 61(5-6), 525-535. https://doi.org/10.7754/Clin. Lab.2014.141005

Dieamant, F., Petersen, C. G., Mauri, A. L., Conmar, V., Mattila, M., Vagnini, L. D., ... Franco, J. G. Jr. (2017). Semen parameters in men with varicocele: DNA fragmentation, chromatin packaging, mitochondrial membrane potential, and apoptosis. JBRA Assisted Reproduction, 21(4), 295-301. https://doi.org/10.5935/1518-0557.20170053

Domínguez-Fandos, D., Camejo, M. I., Ballescà, J. L., \& Oliva, R. (2007). Human sperm DNA fragmentation: Correlation of TUNEL results as assessed by flow cytometry and optical microscopy. Cytometry Part A, 71(12), 1011-1018. https://doi.org/10.1002/cyto.a.20484

Douglas, C., Parekh, N., Kahn, L. G., Henkel, R., \& Agarwal, A. (2019). A novel approach to improving the reliability of manual semen analysis: A paradigm shift in the workup of infertile men. World Journal of Men's Health, 37, e60. https://doi.org/10.5534/wjmh.190088 
Dupont, C., Faure, C., Sermondade, N., Boubaya, M., Eustache, F. Clément, P., ... Levy, R. (2013). Obesity leads to higher risk of sperm DNA damage in infertile patients. Asian Journal of Andrology, 15(5), 622-625. https://doi.org/10.1038/aja.2013.65

Duran, E. H. (2002). Sperm DNA quality predicts intrauterine insemination outcome: A prospective cohort study. Human Reproduction, 17(12), 3122-3128. https://doi.org/10.1093/humrep/17.12.3122

Erenpreiss, J., Spano, M., Erenpreisa, J., Bungum, M., \& Giwercman, A. (2006). Sperm chromatin structure and male fertility: Biological and clinical aspects. Asian Journal of Andrology, 8(1), 11-29. https://doi. org/10.1111/j.1745-7262.2006.00112.x

Esteves, S. C. (2019). Interventions to prevent sperm DNA damage effects on reproduction. Advances in Experimental Medicine and Biology, 1166, 119-148.

Evenson, D. P. (1999). Utility of the sperm chromatin structure assay as a diagnostic and prognostic tool in the human fertility clinic. Human Reproduction, 14(4), 1039-1049. https://doi.org/10.1093/humre $\mathrm{p} / 14.4 .1039$

Evenson, D., \& Wixon, R. (2006). Meta-analysis of sperm DNA fragmentation using the sperm chromatin structure assay. Reproductive BioMedicine Online, 12(4), 466-472. https://doi.org/10.1016/S1472 -6483(10)62000-7

Fernández, J., Muriel, L., Goyanes, V., Segrelles, E., Gosálvez, J., Enciso, M., ... De Jonge, C. (2005). Simple determination of human sperm DNA fragmentation with an improved sperm chromatin dispersion test. Fertility and Sterility, 84(4), 833-842. https://doi.org/10.1016/j. fertnstert.2004.11.089

Fernández, J. L., Muriel, L., Rivero, M. T., Goyanes, V., Vazquez, R., \& Alvarez, J. G. (2003). The sperm chromatin dispersion test: A simple method for the determination of sperm DNA fragmentation. Journal of Andrology, 24(1), 59-66.

Frajese, G., Silvestroni, L., Malandrino, F., \& Isidori, A. (1976). High deoxyribonucleic acid content of spermatozoa from infertile. Oligospermic Human Males. Fertility and Sterility, 27(1), 14-20. https://doi. org/10.1016/S0015-0282(16)41590-6

Giwercman, A., Lindstedt, L., Larsson, M., Bungum, M., Spano, M., Levine, R. J., \& Rylander, L. (2010). Sperm chromatin structure assay as an independent predictor of fertility in vivo: A case-control study. International Journal of Andrology, 33(1), e221-e227. https://doi. org/10.1111/j.1365-2605.2009.00995.x

Gosálvez, J., González-Martínez, M., López-Fernández, C., Fernández, J. L., \& Sánchez-Martín, P. (2011). Shorter abstinence decreases sperm deoxyribonucleic acid fragmentation in ejaculate. Fertility and Sterility, 96(5), 1083-1086. https://doi.org/10.1016/j.fertn stert.2011.08.027

Greco, E., Romano, S., lacobelli, M., Ferrero, S., Baroni, E., Minasi, M. G. ... Tesarik, J. (2005). ICSI in cases of sperm DNA damage: Beneficial effect of oral antioxidant treatment. Human Reproduction, 20(9), 2590-2594. https://doi.org/10.1093/humrep/dei091

Gual-Frau, J., Abad, C., Amengual, M. J., Hannaoui, N., Checa, M. A., Ribas-Maynou, J., ... Prats, J. (2015). Oral antioxidant treatment partly improves integrity of human sperm DNA in infertile grade $i$ varicocele patients. Human Fertility, 18(3), 225-229. https://doi. org/10.3109/14647273.2015.1050462

Gupta, S., Sharma, R., \& Agarwal, A. (2017). Inter-and intra-laboratory standardization of TUNEL assay for assessment of sperm DNA fragmentation. Current Protocols in Toxicology, 74), 1-16. https://doi. org/10.1002/cptx.37

Hendin, B. N., Kolettis, P. N., Sharma, R. K., Thomas, A. J. Jr, \& Agarwal, A. (1999). Varicocele is associated with elevated spermatozoal reactive oxygen species production and diminished seminal plasma antioxidant capacity. Journal of Urol, 161(6), 1831-2184. https://doi. org/10.1016/S0022-5347(05)68818-0

Lanzafame, F., La Vignera, S., Vicari, E., \& Calogero, A. E. (2009). Oxidative stress and medical antioxidant treatment in male infertility. Reproductive BioMedicine Online, 19(5), 638-659. https:// doi.org/10.1016/j.rbmo.2009.09.014

Lara-Cerrillo, S., Gual-Frau, J., Benet, J., Abad, C., Prats, J., Amengual, M. J., ... García-Peiró, A. (2020). Microsurgical varicocelectomy effect on sperm telomere length, DNA fragmentation and seminal parameters. Human Fertility, 9, 1-7. https://doi.org/10.1080/14647 273.2019.1711204

Lewis, S. E. M., \& Agbaje, I. M. (2008). Using the alkaline comet assay in prognostic tests for male infertility and assisted reproductive technology outcomes. Mutagenesis, 23(3), 163-170. https://doi. org/10.1093/mutage/gem052

Lin, J., Dhabuwala, C., \& Li, H. (2001). The role of apoptosis in infertile men with varicoceles: Is the FAS system implicated? Fertility and Sterility, 76(3), S197. https://doi.org/10.1016/S0015-0282(01)02585 $-7$

Mahfouz, R., Sharma, R., Thiyagarajan, A., Kale, V., Gupta, S., Sabanegh, E., \& Agarwal, A. (2010). Semen characteristics and sperm DNA fragmentation in infertile men with low and high levels of seminal reactive oxygen species. Fertility and Sterility, 94(6), 2141-2146. https:// doi.org/10.1016/j.fertnstert.2009.12.030

Majzoub, A., Agarwal, A., \& Esteves, S. C. (2017). Sperm DNA fragmentation in clinical practice. Translational Andrology and Urology, 6, S544-S546. https://doi.org/10.21037/tau.2017.03.13

Malić Vončina, S., Golob, B., Ihan, A., Kopitar, A. N., Kolbezen, M., \& Zorn, B. (2016). Sperm DNA fragmentation and mitochondrial membrane potential combined are better for predicting natural conception than standard sperm parameters. Fertility and Sterility, 105, 637-644. https://doi.org/10.1016/j.fertnstert.2015.11.037

Mandani, P., Desai, K., \& Highland, H. (2013). Cytotoxic effects of benzene metabolites on human sperm function: An in vitro study. ISRN Toxicology, 2013, 397524.

Marchiani, S., Tamburrino, L., Olivito, B., Betti, L., Azzari, C., Forti, G., .. Muratori, M. (2014). Characterization and sorting of flow cytometric populations in human semen. Andrology, 2(3), 394-401. https://doi. org/10.1111/j.2047-2927.2014.00208.x

Mitchell, L. A., De luliis, G. N., \& Aitken, R. J. (2011). The TUNEL assay consistently underestimates DNA damage in human spermatozoa and is influenced by DNA compaction and cell vitality: Development of an improved methodology. International Journal of Andrology, 34, 2-13. https://doi.org/10.1111/j.1365-2605.2009.01042.x

Morris, I. D., Ilott, S., Dixon, L., \& Brison, D. R. (2002). The spectrum of DNA damage in human sperm assessed by single cell gel electrophoresis (Comet assay) and its relationship to fertilization and embryo development. Human Reproduction, 17(4), 990-998. https://doi. org/10.1093/humrep/17.4.990

Mostafa, T., Tawadrous, G., Roaia, M. M., Amer, M. K., Kader, R. A., \& Aziz, A. (2006). Effect of smoking on seminal plasma ascorbic acid in infertile and fertile males. Andrologia., 38(6), 221-224. https://doi. org/10.1111/j.1439-0272.2006.00744.x

Muratori, M., Marchiani, S., Tamburrino, L., Cambi, M., Lotti, F., Natali, I., ... Baldi, E. (2015). DNA fragmentation in brighter sperm predicts male fertility independently from age and semen parameters. Fertility and Sterility, 104(3), 582-590.e4. https://doi.org/10.1016/j. fertnstert.2015.06.005

Muratori, M., Marchiani, S., Tamburrino, L., Tocci, V., Failli, P., Forti, G., \& Baldi, E. (2008). Nuclear staining identifies two populations of human sperm with different DNA fragmentation extent and relationship with semen parameters. Human Reproduction, 23(5), 1035-1043. https://doi.org/10.1093/humrep/den058

Muratori, M., Tamburrino, L., Marchiani, S., Guido, C., Forti, G., \& Baldi, E. (2010). Critical aspects of detection of sperm DNA fragmentation by TUNEL/flow cytometry. Systems Biology in Reproductive Medicine, 56(4), 277-285. https://doi.org/10.3109/19396368.2010.489660

Muriel, L., Meseguer, M., Luis Fernández, J., Alvarez, J., Remohí, J., Pellicer, A., \& Garrido, N. (2006). Value of the sperm chromatin 
dispersion test in predicting pregnancy outcome in intrauterine insemination: A blind prospective study. Human Reproduction, 21(3), 738-744. https://doi.org/10.1093/humrep/dei403

Nallella, K. P., Sharma, R. K., Aziz, N., \& Agarwal, A. (2006). Significance of sperm characteristics in the evaluation of male infertility. Fertility and Sterility, 85(3), 629-634. https://doi.org/10.1016/j.fertn stert.2005.08.024

Nguyen, T. T., Trieu, T. S., Tran, T. O., \& Luong, T. L. A. (2019). Evaluation of sperm DNA fragmentation index, Zinc concentration and seminal parameters from infertile men with varicocele. Andrologia, 51(2), e13184.

Osman, A., Alsomait, H., Seshadri, S., El-Toukhy, T., \& Khalaf, Y. (2015). The effect of sperm DNA fragmentation on live birth rate after IVF or ICSI: A systematic review and meta-analysis. Reproductive BioMedicine Online, 30(2), 120-127. https://doi.org/10.1016/j. rbmo.2014.10.018

Pasqualotto, F. F., Sundaram, A., Sharma, R. K., Borges, E. Jr, Pasqualotto, E. B., \& Agarwal, A. (2008). Semen quality and oxidative stress scores in fertile and infertile patients with varicocele. Fertility and Sterility, 89(3), 602-607. https://doi.org/10.1016/j.fertnstert.2007.03.057

Ribeiro, S. C., Muratori, M., De Geyter, M., \& De Geyter, C. (2017). TUNEL labeling with BrdUTP/anti-BrdUTP greatly underestimates the level of sperm DNA fragmentation in semen evaluation. PLoS One, 12(8), e0181802. https://doi.org/10.1371/journal.pone.0181802

Ribeiro, S. C., Sartorius, G., Pletscher, F., De Geyter, M., Zhang, H., \& De Geyter, C. (2013). Isolation of spermatozoa with low levels of fragmented DNA with the use of flow cytometry and sorting. Fertility and Sterility, 100(3), 686-694. https://doi.org/10.1016/j.fertn stert.2013.05.030

Robinson, L., Gallos, I. D., Conner, S. J., Rajkhowa, M., Miller, D., Lewis, S., ... Coomarasamy, A. (2012). The effect of sperm DNA fragmentation on miscarriage rates: A systematic review and meta-analysis. Human Reproduction, 27(10), 2908-2917. https://doi.org/10.1093/humrep/ $\operatorname{des} 261$

Roque, M., \& Esteves, S. C. (2018). Effect of varicocele repair on sperm DNA fragmentation: A review. International Urology and Nephrology, 50(4), 583-603. https://doi.org/10.1007/s11255-018-1839-4

Rubio, C., Gil-Salom, M., Simón, C., Vidal, F., Rodrigo, L., Mínguez, Y., .. Pellicer, A. (2001). Incidence of sperm chromosomal abnormalities in a risk population: Relationship with sperm quality and ICSI outcome. Human Reproduction, 16(10), 2084-2092. https://doi.org/10.1093/ humrep/16.10.2084

Rubio, C., Simón, C., Blanco, J., Vidal, F., Mínguez, Y., Egozcue, J., ... Pellicer, A. (1999). Implications of sperm chromosome abnormalities in recurrent miscarriage. Journal of Assisted Reproduction and Genetics, 16(5), 253-258.

Sakkas, D., \& Alvarez, J. G. (2010). Sperm DNA fragmentation: Mechanisms of origin, impact on reproductive outcome, and analysis. Fertility and Sterility, 93(4), 1027-1036. https://doi.org/10.1016/j. fertnstert.2009.10.046

Sakkas, D., \& El-Fakahany, H. M. (2018). Apoptosis in ejaculated spermatozoa and in the normal and pathological testes: abortive apoptosis and sperm chromatin damage. In A. Zini, \& A. Agarwal (Eds.), A Clinician's guide to sperm DNA and chromatin damage (pp 197-218). Cham, Switzerland: Springer International Publishing AG.

Sakkas, D. S., Seli, E., Bizzarro, D., Tarozzi, N., \& Manicardi, G. C. (2003). Abnormal spermatozoa in the ejaculate: Abortive apoptosis and faulty nuclear remodelling during spermatogenesis. Reproductive BioMedicine Online, 7(4), 428-432. https://doi.org/10.1016/S1472 -6483(10)61886-X

Saleh, R. A., Agarwal, A., Sharma, R. K., Nelson, D. R., \& Thomas, A. J. Jr. (2002). Effect of cigarette smoking on levels of seminal oxidative stress in infertile men: A prospective study. Fertility and Sterility, 78(3), 491-499. https://doi.org/10.1016/S0015 $-0282(02) 03294-6$
Saleh, R. A., Agarwal, A., Sharma, R. K., Said, T. M., Sikka, S. C., \& Thomas, A. J. Jr. (2003). Evaluation of nuclear DNA damage in spermatozoa from infertile men with varicocele. Fertility and Sterilty, 80(6), 14311436. https://doi.org/10.1016/S0015-0282(03)02211-8

Santana, V. P., Miranda-Furtado, C. L., Pedroso, D. C. C., Eiras, M. C., Vasconcelos, M. A. C., Ramos, E. S., ... dos Reis, R. M. (2019). The relationship among sperm global DNA methylation, telomere length, and DNA fragmentation in varicocele: A cross-sectional study of 20 cases. Syst Biol Reprod Med, 65(2), 95-104. https://doi.org/10.1080/19396 368.2018.1557762

Segerink, L. I., Sprenkels, A. J., Oosterhuis, G. J. E., Vermes, I., \& van den Berg, A. (2012). Microfluidic chips for semen analysis. EJIFCC, 23(3), 66-69.

Sepaniak, S., Forges, T., Gerard, H., Foliguet, B., Bene, M. C., \& MonnierBarbarino, P. (2006). The influence of cigarette smoking on human sperm quality and DNA fragmentation. Toxicology, 223(1-2), 54-60. https://doi.org/10.1016/j.tox.2006.03.001

Sergerie, M., Laforest, G., Bujan, L., Bissonnette, F., \& Bleau, G. (2005). Sperm DNA fragmentation: Threshold value in male fertility. Human Reproduction, 20(12), 3446-3451. https://doi.org/10.1093/humrep/ dei231

Sharma, R., Ahmad, G., Esteves, S. C., \& Agarwal, A. (2016). Terminal deoxynucleotidyl transferase dUTP nick end labeling (TUNEL) assay using bench top flow cytometer for evaluation of sperm DNA fragmentation in fertility laboratories: Protocol, reference values, and quality control. Journal of Assisted Reproduction and Genetics, 33(22), 291-300. https://doi.org/10.1007/s10815-015-0635-7

Sharma, R., Cakar, Z., \& Agarwal, A. (2018). TUNEL assay by benchtop flow cytometer in clinical laboratories. In A. Zini, \& A. Agarwal (Eds.), A Clinician's guide to sperm DNA and chromatin damage (pp. 103-118). Berlin, Germany: Springer.

Sharma, R., Gupta, S., Henkel, R., \& Agarwal, A. (2019). Critical evaluation of two models of flow cytometers for the assessment of sperm DNA fragmentation: An appeal for performance verification. Asian Journal of Andrology, 21(5), 438-444. https://doi.org/10.4103/aja. aja_109_18

Sharma, R. K., Pasqualotto, F. F., Nelson, D. R., \& Agarwal, A. (2001). Relationship between seminal white blood cell counts and oxidative stress in men treated at an infertility clinic. Journal of Andrology, 22(4), 575-583.

Sharma, R. K., Sabanegh, E., Mahfouz, R., Gupta, S., Thiyagarajan, A., \& Agarwal, A. (2010). TUNEL as a test for sperm DNA damage in the evaluation of male infertility. Urology, 76(6), 1380-1386. https://doi. org/10.1016/j.urology.2010.04.036

Shukla, K. K., Mahdi, A. A., \& Rajender, S. (2012). Apoptosis, spermatogenesis and male infertility. Frontiers in Bioscience (Elite Ed), 4(1), 746754. https://doi.org/10.2741/e415

Simon, L., Zini, A., Dyachenko, A., Ciampi, A., \& Carrell, D. (2017). A systematic review and meta-analysis to determine the effect of sperm DNA damage on in vitro fertilization and intracytoplasmic sperm injection outcome. Asian Journal of Andrology, 19(1), 80-90.

Smith, R., Kaune, H., Parodi, D., Madariaga, M., Rios, R., Morales, I., \& Castro, A. (2006). Increased sperm DNA damage in patients with varicocele: Relationship with seminal oxidative stress. Human Reproduction, 21(4), 986-993. https://doi.org/10.1093/humrep/ dei429

Tanaka, T., Kobori, Y., Terai, K., Inoue, Y., Osaka, A., Yoshikawa, N., ... Okada, H. (2020). Seminal oxidation-reduction potential and sperm DNA fragmentation index increase among infertile men with varicocele. Human Fertility (Cambridge), 20, 1-5. https://doi. org/10.1080/14647273.2020.1712747

Tomlinson, M. J. (2016). Uncertainty of measurement and clinical value of semen analysis: Has standardisation through professional guidelines helped or hindered progress? Andrology, 4(5), 763-770. https:// doi.org/10.1111/andr.12209 
Tomsu, M., Sharma, V., \& Miller, D. (2002). Embryo quality and IVF treatment outcomes may correlate with different sperm comet assay parameters. Human Reproduction, 17, 1856-1862. https://doi. org/10.1093/humrep/17.7.1856

Topping, D., Brown, P., Judis, L., Schwartz, S., Seftel, A., Thomas, A., \& Hassold, T. (2006). Synaptic defects at meiosis I and non-obstructive azoospermia. Human Reproduction, 21(12), 3171-3177. https://doi. org/10.1093/humrep/del281

Tremellen, K. (2008). Oxidative stress and male infertility-a clinical perspective. Human Reproduction, 14(3), 243-258.

Velez de la Calle, J. F., Muller, A., Walschaerts, M., Clavere, J. L., Jimenez, C., Wittemer, C., \& Thonneau, P. (2008). Sperm deoxyribonucleic acid fragmentation as assessed by the sperm chromatin dispersion test in assisted reproductive technology programs: Results of a large prospective multicenter study. Fertility and Sterility, 90(5), 1792-1799. https://doi.org/10.1016/j.fertnstert.2007.09.021

Vogiatzi, P., Chrelias, C., Cahill, D. J., Creatsa, M., Vrachnis, N., Iliodromiti, Z., ... Siristatidis, C. (2013). Hemizona assay and sperm penetration assay in the prediction of IVF outcome: A systematic review. BioMed Research International, 2013, 945825. https://doi. org/10.1155/2013/945825

Wang, Y. J., Zhang, R. Q., Lin, Y. J., Zhang, R. G., \& Zhang, W. L. (2012). Relationship between varicocele and sperm DNA damage and the effect of varicocele repair: A meta-analysis. Reprod Biomed Online, 25(3), 307-314. https://doi.org/10.1016/j.rbmo.2012.05.002

Wdowiak, A., \& Bojar, I. (2016). Relationship between pregnancy, embryo development, and sperm deoxyribonucleic acid fragmentation dynamics. Saudi Journal of Biological Sciences, 23(5), 598-606. https:// doi.org/10.1016/j.sjbs.2015.08.001

Wiweko, B., \& Utami, P. (2017). Predictive value of sperm deoxyribonucleic acid (DNA) fragmentation index in male infertility. Basic Clin Androl, 27, 1. https://doi.org/10.1186/s12610-016-0046-3

World Health Organization. 2010). WHO laboratory manual for the examination and processing of human sperm, 5th edn. Geneva: World Health Organization.
Wright, C., Milne, S., \& Leeson, H. (2014). Sperm DNA damage caused by oxidative stress: Modifiable clinical, lifestyle and nutritional factors in male infertility. Reproductive Biomedicine Online, 28(6), 684-703. https://doi.org/10.1016/j.rbmo.2014.02.004

Wu, D., \& Cederbaum, A. I. (2003). Alcohol, oxidative stress, and free radical damage. Alcoh Res Health, 27(4), 277-284.

Zhu, Z-J, Dong, X-Y, Liang, J-J, Zhang, J-Q, Hu, X-Y, \& Li, L-K, \& (2017). Effects of diabetes mellitus on semen quality in adult men: a systematic review and meta-analysis. Int J Clin Exp Med, 10(8), 11290-11303.

Zini, A., \& Al-Hathal, N. (2011). Antioxidant therapy in male infertility: Fact or fiction? Asian Journal of Andrology, 13(3), 374-381. https:// doi.org/10.1038/aja.2010.182

Zini, A., \& Dohle, G. (2011). Are varicoceles associated with increased deoxyribonucleic acid fragmentation? Fertility and Sterility, 96(6), 1283-1287. https://doi.org/10.1016/j.fertnstert.2011.10.016

Zini, A., Fischer, M. A., Sharir, S., Shayegan, B., Phang, D., \& Jarvi, K. (2002). Prevalence of abnormal sperm DNA denaturation in fertile and infertile men. Urology, 60(6), 1069-1072. https://doi.org/10.1016/S0090 $-4295(02) 01975-1$

Zini, A., \& Sigman, M. (2009). Are tests of sperm DNA damage clinically useful? Pros and cons. Journal of Andrology, 30(3), 219-229. https:// doi.org/10.2164/jandrol.108.006908

How to cite this article: Sharma R, lovine C, Agarwal A, Henkel R. TUNEL assay-Standardized method for testing sperm DNA fragmentation. Andrologia. 2021;53:e13738. https://doi. org/10.1111/and.13738 